\title{
The Asymmetric Influence of Ocean Heat Content on ENSO Predictability in the CNRM-CM5 Coupled General Circulation Model
}

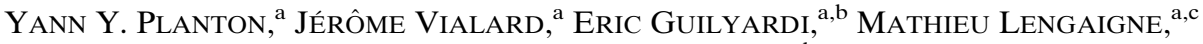 \\ AND MICHAEL J. MCPHADEN ${ }^{\mathrm{d}}$ \\ ${ }^{a}$ LOCEAN-IPSL, CNRS-IRD-MNHN-Sorbonne Université, Paris, France \\ ${ }^{\mathrm{b}}$ NCAS-Climate, University of Reading, Reading, United Kingdom \\ ${ }^{\mathrm{c}}$ MARBEC, University of Montpellier, CNRS, IFREMER, IRD, Sète, France \\ ${ }^{\mathrm{d}}$ NOAA/Pacific Marine Environmental Laboratory, Seattle, Washington
}

(Manuscript received 12 August 2020, in final form 26 February 2021)

\begin{abstract}
Unusually high western Pacific Ocean oceanic heat content often leads to El Niño about 1 year later, while unusually low heat content leads to La Niña. Here, we investigate if El Niño-Southern Oscillation (ENSO) predictability also depends on the initial state recharge, and we discuss the underlying mechanisms. To that end, we use the CNRM-CM5 model, which has a reasonable representation of the main observed ENSO characteristics, asymmetries, and feedbacks. Observations and a 1007-yr-long CNRM-CM5 simulation indicate that discharged states evolve more systematically into La Niña events than recharged states into neutral states or El Niño events. We ran 70-member ensemble experiments in a perfect-model setting, initialized in boreal autumn from either recharged or discharged western Pacific heat content, sampling the full range of corresponding ENSO phases. Predictability measures based both on spread and signal-to-noise ratio confirm that discharged states yield a more predictable ENSO outcome one year later than recharged states. As expected from recharge oscillator theory, recharged states evolve into positive central Pacific sea surface temperature anomalies in boreal spring, inducing stronger and more variable westerly wind event activity and a fast growth of the ensemble spread during summer and autumn. This also enhances the positive wind stress feedback in autumn, but the effect is offset by changes in thermocline and heat flux feedbacks. The state-dependent component of westerly wind events is thus the most likely cause for the predictability asymmetry in CNRM-CM5, although changes in the low-frequency wind stress feedback may also contribute.
\end{abstract}

KEYWORDS: Pacific Ocean; Atmosphere-ocean interaction; ENSO; Seasonal forecasting; Climate models; Interannual variability

\section{Introduction}

El Niño-Southern Oscillation (ENSO) is the most energetic climate phenomenon at interannual time scales on Earth [see McPhaden et al. (2020) for a review]. The positive El Niño phase of ENSO is characterized by positive sea surface temperature anomalies (SSTA) in the central and eastern equatorial Pacific, which generally start in late spring, peak at the end of the calendar year and recede during the following winter. The cold La Niña phase of ENSO broadly exhibits an opposite SSTA signature. ENSO can significantly affect the global atmospheric circulation (Taschetto et al. 2020), causing droughts and floods (Goddard and Gershunov 2020), modulating globally averaged annual surface air temperature and tropical cyclone activity (Lin et al. 2020), and impacting ecosystems and agriculture worldwide (Bertrand et al. 2020; Holbrook et al. 2020).

Because of its many global impacts, it is critical to accurately predict ENSO as early as possible. The recharge oscillator

Planton's current affiliation: NOAA/Pacific Marine Environmental Laboratory, Seattle, Washington.

Corresponding author: Yann Y. Planton, yann.planton@locean-ipsl. upmc.fr theory inspired from Wyrtki (1985) and formulated by Jin (1997) articulates the key role of the western equatorial Pacific heat content, measured by the volume of water warmer than $20^{\circ} \mathrm{C}\left(\mathrm{WWV}_{W}\right)$ or the depth-averaged temperature in the upper $300 \mathrm{~m}$ ( $\mathrm{T} 300_{W}$; see the appendix $)$ as an ENSO precursor. At the peak of an El Niño, there are westerly wind anomalies and negative heat content anomalies (or "discharge") in the western Pacific. This induces a poleward Sverdrup transport that progressively builds up negative heat content anomalies in the central Pacific, leading to cold SSTA through the thermocline and advective feedbacks (Jin and An 1999). These SSTA are then amplified into a La Niña event at the end of the year through the Bjerknes air-sea coupled feedback loop (Bjerknes 1969), involving a positive feedback from the atmospheric wind response (the wind stress feedback) and negative feedback from air-sea fluxes (the heat flux feedback). Atmospheric highfrequency variability, mainly in the form of synoptic shortlived westerly wind events (WWEs; Lengaigne et al. 2004) that are unpredictable at long lead times, is thought to be one of the key elements that introduces some irregularity to this cycle. Representing stochastic forcing associated with WWE in the recharge oscillator model leads to less regular oscillations, as in the real world (Jin et al. 2007), and therefore limits ENSO predictability.

This role of the oceanic state for ENSO predictability has enabled skillful dynamical and statistical ENSO forecasts three 
seasons or more before its peak (e.g., Barnston et al. 2019; L'Heureux et al. 2020). However, these predictions exhibit a rapid decrease in skill when forecasts are initiated in spring or before, due to the so-called spring predictability barrier (e.g., Webster and Yang 1992; Barnston et al. 2019). A clear and recent illustration is the situation during early 2014, when a high recharge prompted speculation of an upcoming strong El Niño that never materialized (McPhaden 2015), while the same early-year conditions led to a strong event in 2015. On the other hand, large discharges (i.e., negative equatorial Pacific heat content anomalies) appear to be associated with predictable evolution toward La Niña up to 2 years in advance (DiNezio et al. 2017a,b). This raises an important question. Is ENSO future evolution more predictable from a discharged than from a recharged equatorial Pacific? Answering this question has a considerable practical utility, as this would give forecasters additional information on the reliability of forecasts.

There is to date no consensus about a potential dependence of ENSO predictability on ENSO state. Some analyses based on observations (Timmermann et al. 2018) and ensemble experiments in a perfect model framework (Larson and Kirtman 2019) suggest that El Niño is more predictable than La Niña. Alternatively, other studies using the conceptual recharge oscillator model (Jin et al. 2007), a simplified model (Dommenget et al. 2013), and coupled general circulation models (Lopez and Kirtman 2014; DiNezio et al. 2017a,b; Planton et al. 2018; Yu and Fedorov 2020) point toward an enhanced predictability of La Niña events. Finally, real-time seasonal ENSO forecasts initialized using oceanic observations indicate that El Niño and La Niña events are equally predictable (Larson and Pegion 2020). Some of the studies above address the potential asymmetry in predictability by exploring 1) which phase of ENSO is most predictable, while others instead investigate 2) which initial states are associated with most predictability. As discussed in Larson and Pegion (2020), we believe that the second question is better posed and more useful in a real-time prediction scenario. Knowing the current state of the ocean, we want to know how predictable the following ENSO evolution is and not whether a particular event was predictable once it has occurred.

The current study is based on Planton et al. (2018). This study investigated potential asymmetries in the predictability of ENSO phase transitions by looking at the statistical relationship between $\mathrm{T} 300_{W}$ anomalies $\left(\mathrm{T} 300_{W} \mathrm{~A}\right)$ and the upcoming ENSO amplitude. $\mathrm{T} 300_{W} \mathrm{~A}$ was used, rather than the more widely used anomalies of T300 averaged over the entire equatorial Pacific (EP T300A), because several studies indicate it is a better indicator of the low-frequency "memory" from the previous ENSO phase (e.g., Wyrtki 1985; Jin 1997; McGregor et al. 2016; Neske and McGregor 2018; Izumo et al. 2019). Planton et al. (2018) found that discharged boreal autumn $\mathrm{T} 300_{W} \mathrm{~A}$ generally leads to a La Niña about 1 year later, but that a recharged state leads to a much wider distribution of ENSO outcomes. They found this asymmetry both in observations and models from phase 5 of the Coupled Model Intercomparison Project (CMIP5; Taylor et al. 2012) database. While this statistical analysis suggests a more predictable evolution toward La Niña in presence of a discharged $\mathrm{T} 300_{W} \mathrm{~A}$, it did not address the question of what mechanisms accounted for the asymmetry in predictability.
Several ENSO mechanisms are nonlinear [see An et al. (2020) for a review] and may therefore lead to asymmetries in ENSO properties and predictability. First, there are nonlinearities in the Bjerknes air-sea feedback loop, and hence to the low-frequency stability of the system. While the thermocline feedback (e.g., Jin and An 1999) usually has similar amplitude during both phases of ENSO (e.g., Guan et al. 2019), the positive wind stress feedback and negative heat flux feedback are both stronger during El Niño, due to the enhanced activation of atmospheric deep convection at high surface temperatures (e.g., Guilyardi et al. 2009; Frauen and Dommenget 2010; Choi et al. 2013; Im et al. 2015; Takahashi and Dewitte 2016) and enhanced cloud cover (e.g., Lloyd et al. 2012; Im et al. 2015). Second, stochastic forcing associated with WWEs is also nonlinear and dependent on the ENSO state. WWEs are indeed modulated by the zonal extension of the warm pool and are more frequent and/or more intense during El Niño than during La Niña (e.g., Lengaigne et al. 2004; Eisenman et al. 2005; Gebbie et al. 2007). This nonlinearity, also referred to as a multiplicative or state-dependent noise forcing, induces larger (e.g., Levine et al. 2016; Martinez-Villalobos et al. 2019) and less predictable (Jin et al. 2007; Lopez and Kirtman 2014) El Niño than La Niña events in conceptual models of ENSO.

In this paper, we explore the influence of the western equatorial Pacific heat content T300 ${ }_{W} \mathrm{~A}$ on ENSO predictability and its mechanism in the CNRM-CM5 climate model. This model reproduces the main ENSO main characteristics reasonably well, including its asymmetry and the asymmetrical relationship between $\mathrm{T} 300_{W} \mathrm{~A}$ and the upcoming ENSO amplitude found in Planton et al. (2018). We perform a number of 70-member ensemble experiments, where ensembles are generated through infinitesimal perturbations of initial conditions. Initial conditions from these experiments either correspond to recharged or discharged boreal autumn $\mathrm{T} 300_{W} \mathrm{~A}$, and we run a total of six ensembles that span different ENSO phases (a recharged T300 ${ }_{W} \mathrm{~A}$ can for instance correspond to neutral, El Niño or strong El Niño phases). In section 2, we briefly present the datasets and method used in the paper (a more detailed description is provided in the appendix). In section 3, we assess ENSO in CNRM-CM5 versus the rest of the CMIP database and observations, focusing on important ENSO properties and feedbacks for the current study. In section 4, we present the results of the ensemble experiments and propose a mechanism explaining the asymmetry in predictability. In section 5 we provide a summary, and in section 6 we compare our results with those of previous studies.

\section{Data and methods}

\section{a. Models and datasets}

This study uses a 1007-yr simulation (after a 200-yr spinup) with the CNRM-CM5 model [see the appendix and Voldoire et al. (2013) for more description of the model], with greenhouse gas concentrations and solar irradiance fixed to their observed value for 1850, as in CMIP5 preindustrial control (piControl) simulations (Taylor et al. 2012). To evaluate CNRM-CM5 with respect to other coupled climate models and observations, we compare its performance with 44 CMIP5 
models and 36 CMIP6 models (Eyring et al. 2016) for which a piControl simulation was available at the time of writing this paper (see Table 1 for the list of models and data availability). These simulations are evaluated against the NCEP GODAS oceanic reanalysis data (Saha et al. 2006) for T300 anomalies (T300A) and TropFlux dataset (Praveen Kumar et al. 2012, 2013) for SSTA, zonal wind stress anomalies (TauxA), and net heat flux anomalies at the air-sea interface (NHFA). We use monthly values of these products for the period 1980-2018, except for the detection of WWE, which is based on daily zonal wind stress. Interannual anomalies are computed by removing the mean monthly seasonal cycle, except for the warm pool eastern edge (WPEE) and WWE index discussed below, for which absolute values are shown.

\section{b. Ensemble experiments design}

ENSO ensemble forecasts experiments are designed in a perfect model setting. Ensembles consist of 70-member experiments starting on 1 November, and lasting for 17 months (i.e., until the end of March, two years later), generated by applying small-amplitude random white noise perturbations on the initial SST as in Puy et al. (2019). This perfect model forecast setting provides a "best case scenario" for predictions, where the spread essentially arises from the coupled system chaotic behavior. This setting hence does not include the effects of uncertainties in initial oceanic conditions nor the effect of model errors, which are a limitation in real-time seasonal ENSO forecasts (as in Larson and Pegion 2020). We chose to start our ensemble on 1 November to test whether the longlead memory of the ocean can lead to asymmetrical predictability of El Niño and La Niña, building on Planton et al. (2018). The set of oceanic initial conditions from which the ensemble experiments are initiated is picked from the 1007-yrlong control simulation and detailed in section 4 .

\section{c. ENSO and preconditioning indices}

We define the ENSO state using the average boreal winter [November-January ( NDJ)] Niño-3 (N3; 90-150 $\mathrm{W}, 5^{\circ} \mathrm{S}-$ $5^{\circ} \mathrm{N}$ ) SSTA normalized by the dataset's standard deviation. The ENSO state is defined as an extreme La Niña event for N3 SSTA below -1.5 , a moderate La Niña event between -1.5 and -0.5 , a neutral "event" between -0.5 and 0.5 , a moderate El Niño event between 0.5 and 1.5, and an extreme El Niño event above 1.5. We define the ocean preconditioning from the $\mathrm{T} 300_{W} \mathrm{~A}$, averaged over the western equatorial Pacific and normalized by their standard deviation (see the appendix for details). To account for the model "cold tongue bias" (see Fig. A1 in the appendix), the western Pacific box in CNRMCM5 model $\left(120^{\circ} \mathrm{E}-180^{\circ}, 5^{\circ} \mathrm{S}-5^{\circ} \mathrm{N}\right)$ has a westward-shifted eastern boundary relative to that commonly used for observations $\left(120^{\circ} \mathrm{E}-155^{\circ} \mathrm{W}, 5^{\circ} \mathrm{S}-5^{\circ} \mathrm{N}\right)$. We use similar thresholds to those above for defining extreme discharge, moderate discharge, neutral preconditioning, moderate recharge, and extreme recharge based on the normalized $\mathrm{T} 300_{W} \mathrm{~A}$ value.

\section{d. Essential ENSO characteristics}

A set of metrics that evaluate essential ENSO properties (including asymmetries between El Niño and La Niña events) in the CNRM-CM5 model is used in this paper. These metrics are defined as follows:

- amplitude: standard deviation of N3 SSTA during NDJ,

- seasonality: standard deviation of N3 SSTA during NDJ divided by March-May (MAM),

- amplitude symmetry: Fisher-Pearson coefficient of skewness (Kokoska and Zwillinger 2000),

- duration asymmetry: mean duration of La Niña events divided by that of El Niño events, where the duration is the number of consecutive months with normalized absolute SSTA above 0.25 ENSO amplitude (i.e., the value of the first metric), and

- transition asymmetry: percentage of El Niño events followed the next winter by La Niña events divided by the percentage of La Niña events followed the next winter by El Niño events.

\section{e. Diagnosing ENSO processes}

The three feedbacks used in this paper are defined as the linear regression coefficient of: averaged Niño-4 (N4; $160^{\circ} \mathrm{E}-$ $150^{\circ} \mathrm{W}, 5^{\circ} \mathrm{S}-5^{\circ} \mathrm{N}$ ) TauxA onto averaged N3 SSTA (wind stress feedback; e.g., Bellenger et al. 2014), N3 NHFA onto averaged N3 SSTA (heat flux feedback; e.g., Lloyd et al. 2009), and averaged N3 T300A onto averaged N3 SSTA (thermocline feedback; e.g., Bayr et al. 2019),

The Puy et al. (2016) method is applied to detect WWEs in observations and our CNRM-CM5 simulations. WWEs are detected as $2^{\circ} \mathrm{N}-2^{\circ} \mathrm{S}$ average intraseasonally filtered (5-90-day period) daily wind stress exceeding $0.04 \mathrm{~N} \mathrm{~m}^{-2}$ over more than $10^{\circ}$ longitude and 5 days. WWE separated by less than $3^{\circ}$ and 3 days and are grouped as a single event. Weighted averages are used to define the locations and dates of WWEs. The intensity of each WWE is defined as the space-time integration of the intraseasonally filtered TauxA over the wind event patch. The intensity of each WWE is then normalized by its standard deviation to create a "wind event intensity" (WEI) index, as in Puy et al. (2016), who showed that it is a proxy of the oceanic Kelvin wave response. Some previous authors (e.g., Chiodi et al. 2014; Yu and Fedorov 2020) have argued that wind events should be detected based on interannual wind stress forcing rather than intraseasonally filtered forcing like we do. One of our motivations for using intraseasonally filtered wind stress to detect WWE is to reduce the WEI dependency on the interannual wind stress signal and hence on the Bjerknes wind stress feedback. We checked our results using both definitions and found that our conclusions do not fundamentally change (not shown).

As mentioned in the introduction, WWE activity is modulated by the zonal displacements of the warm pool (e.g., Lengaigne et al. 2004; Eisenman et al. 2005; Gebbie et al. 2007). The WPEE is defined as the location of the $28.5^{\circ} \mathrm{C}$ isotherm in observations and the $27.5^{\circ} \mathrm{C}$ isotherm in the model, because of the $\sim 1^{\circ} \mathrm{C}$ cold equatorial bias in CNRM-CM5 (Voldoire et al. 2013; Planton et al. 2020).

Recent studies have suggested that easterly wind events (EWEs) could also play a role for triggering La Niña events (e.g., Chiodi and Harrison 2015). This aspect is, however, less documented than the very clear WWE-ENSO two-way 
TABLE 1. CMIP5 and CMIP6 model names and associated modeling centers. Expansions for many of the models and modeling centers can be found online (https://www.ametsoc.org/PubsAcronymList).

\begin{tabular}{|c|c|c|c|c|}
\hline \multirow[b]{2}{*}{ Modeling center } & \multicolumn{2}{|c|}{ CMIP5 } & \multicolumn{2}{|c|}{ CMIP6 } \\
\hline & Model & Run length (yr) & Model & Run length (yr) \\
\hline AWI & - & - & AWI-CM-1-1-MR ${ }^{\mathrm{c}}$ & 500 \\
\hline \multirow{2}{*}{$\mathrm{BCC}$} & BCC_CSM1.1 & 500 & BCC-CMS2-MR & 600 \\
\hline & BCC_CSM1.1(m) & 400 & BCC-EMS1 ${ }^{\mathrm{c}}$ & 451 \\
\hline BNU & BNU-ESM ${ }^{\mathrm{b}}$ & 558 & - & - \\
\hline CAMS & - & - & CAMS-CSM1-0 & 500 \\
\hline \multirow{2}{*}{ CAS } & - & - & FGOALS-f3-L $\mathrm{L}^{\mathrm{a}, \mathrm{c}}$ & 561 \\
\hline & - & - & FGOALS-g $3^{\mathrm{c}}$ & 700 \\
\hline CCCma & CanESM2 & 996 & CanESM5 & 1000 \\
\hline CCCR-IITM & - & - & IITM-ESM & 200 \\
\hline \multirow[t]{3}{*}{$\mathrm{CMCC}$} & CMCC-CESM & 277 & - & - \\
\hline & CMCC-CM & 290 & - & - \\
\hline & CMCC-CMS & 500 & - & - \\
\hline \multirow[t]{3}{*}{ CNRM-CERFACS } & ${\mathrm{CNRM}-\mathrm{CM} 5^{\mathrm{c}}}$ & 850 & CNRM-CM6-1 & 500 \\
\hline & CNRM-CM5-2 & 359 & CNRM-CM6-1-HR & 500 \\
\hline & - & - & CNRM-ESM2-1 & 300 \\
\hline \multirow[t]{2}{*}{ CSIRO-ARCCSS and CSIRO-BoM } & ACCESS1.0 & 500 & ACCESS-CM2 $2^{\mathrm{a}, \mathrm{b}, \mathrm{c}}$ & 500 \\
\hline & ACCESS1.3 & 500 & - & - \\
\hline CSIRO-QCCCE & CSIRO Mk3.6.0 & 500 & - & - \\
\hline \multirow[t]{2}{*}{ E3SM-Project } & - & - & E3SM-1- $0^{\mathrm{c}}$ & 500 \\
\hline & - & - & E3SM-1-1 & 165 \\
\hline FIO-QLNM and FIO & FIO-ESM ${ }^{\mathrm{a}}$ & 800 & FIO-ESM-1-0 & 575 \\
\hline ICHEC & EC-EARTH $^{\mathrm{a}, \mathrm{c}}$ & 452 & - & - \\
\hline INM & INM-CM4 & 500 & - & - \\
\hline \multirow[t]{3}{*}{ IPSL } & IPSL-CM5A-LR & 430 & IPSL-CM6A-LR ${ }^{c}$ & 2000 \\
\hline & IPSL-CM5A-MR & 300 & - & - \\
\hline & IPSL-CM5B-LR & 300 & - & - \\
\hline LASG-CESS & FGOALS-g2 & 700 & - & - \\
\hline \multirow[t]{4}{*}{ MIROC } & MIROC-ESM ${ }^{\mathrm{c}}$ & 630 & MIROC-ES2L ${ }^{c}$ & 500 \\
\hline & MIROC-ESM-CHEM ${ }^{\mathrm{c}}$ & 255 & MIROC6 $^{\mathrm{c}}$ & 800 \\
\hline & MIROC $4 \mathrm{~h}^{\mathrm{c}}$ & 100 & - & - \\
\hline & MIROC $^{\mathrm{c}}$ & 870 & - & - \\
\hline \multirow[t]{3}{*}{$\mathrm{MOHC}$} & HadGEM2-CC & 240 & HadGEM2-GC31-LL & 500 \\
\hline & HadGEM2-ES & 336 & HadGEM2-GC31-MM ${ }^{\mathrm{c}}$ & 500 \\
\hline & - & - & UKSEM-1-0-LL & 750 \\
\hline \multirow[t]{3}{*}{ MPI } & MPI-ESM-LR & 1000 & MPI-ESM1-2-HR & 500 \\
\hline & MPI-ESM-MR & 1000 & - & - \\
\hline & MPI-ESM-P & 1156 & - & - \\
\hline MRI & MRI-CGCM $3^{c}$ & 500 & MRI-ESM2-0 ${ }^{c}$ & 701 \\
\hline \multirow[t]{4}{*}{ NASA-GISS } & GISS-E2-H & 540 & GISS-E2-1-G & 851 \\
\hline & GISS-E2-H-CC & 251 & - & - \\
\hline & GISS-E2-R & 550 & - & - \\
\hline & GISS-E2-R-CC & 251 & - & - \\
\hline \multirow[t]{5}{*}{ NCAR and NSF-DOE-NCAR } & CCSM4 & 501 & CESM2 & 1200 \\
\hline & CESM1(BGC) & 500 & CESM2-FV2 & 500 \\
\hline & CESM1(CAM5) & 319 & CESM2-WACCM & 499 \\
\hline & CESM1(FASTCHEM) & 222 & CESM2-WACCM-FV2 & 500 \\
\hline & CESM1(WACCM) & 200 & - & - \\
\hline \multirow[t]{3}{*}{$\mathrm{NCC}$} & NorESM1-M & 501 & NorCPM1 & 500 \\
\hline & NorESM1-ME ${ }^{\mathrm{c}}$ & 252 & NorESM1-F ${ }^{c}$ & 200 \\
\hline & - & - & NorESM2-LM ${ }^{\mathrm{c}}$ & 501 \\
\hline NIMR-KMA & HadGEM2-AO ${ }^{\mathrm{a}, \mathrm{c}}$ & 700 & - & - \\
\hline \multirow[t]{3}{*}{ NOAA-GFDL } & GFDL CM3 & 500 & GFDL-CM4 ${ }^{\mathrm{a}}$ & 500 \\
\hline & GFDL-ESM2G & 500 & GFDL-ESM4 $4^{\mathrm{a}}$ & 500 \\
\hline & GFDL-ESM2M & 500 & - & - \\
\hline NUIST & - & - & NESM $^{\mathrm{a}}$ & 300 \\
\hline SNU & - & - & SAM0-UNICON & 700 \\
\hline UA & - & - & MCM-UA-1-0 $0^{\mathrm{a}}$ & 500 \\
\hline
\end{tabular}

${ }^{a}$ Models for which data for the computation of heat flux feedbacks were not available.

${ }^{\mathrm{b}}$ Models for which data for the computation of wind stress feedbacks were not available.

${ }^{\mathrm{c}}$ Models for which data for the computation of thermocline feedbacks were not available. 


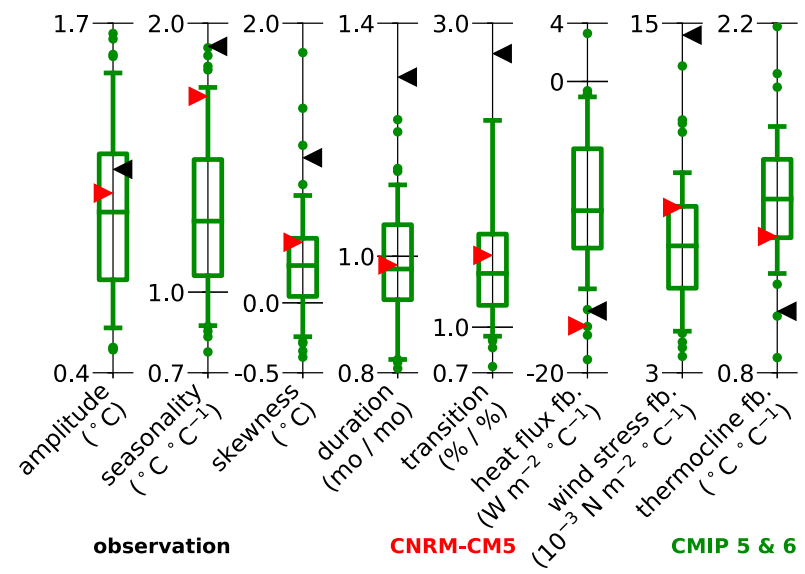

FIG. 1. Scalar measures of key ENSO properties: ENSO amplitude and seasonality; El Niño-La Niña asymmetries in amplitude, duration, and transition; and heat flux, wind stress, and thermocline feedbacks (see the appendix for the definition of these metrics) in the observations (black triangles), the CNRM-CM5 (red triangles), and 80 CMIP models (44 CMIP5 and 36 CMIP6 datasets) (green box-and-whiskers plots; the list of models is in Table 1). Whiskers delineate the 5 th and 95 th percentiles, boxes delineate the 25 th and 75 th percentiles, lines within the boxes mark the median, and dots indicate models that fall outside the whiskers.

interaction. In addition, Puy et al. (2016) showed that the EWE activity modulation by the WPEE displacement depends on the wind event detection method: there is no modulation when EWEs are detected based on filtered wind stress. For these reasons, we decided to focus on the better documented WWEENSO interaction and EWEs are not discussed further in this paper.

\section{f. Predictability metrics}

In this paper, we use two different metrics of ENSO predictability, computed from the ensemble boreal winter N3 SSTA (NDJ). One metric is based on the spread of the ensemble relative to the climatological spread [potential predictability (PP)] and another one on the signal-to-noise ratio (SNR; with signal estimated from the ensemble mean and noise from the ensemble spread; see the appendix for the exact definitions). In both cases, the ensemble spread is quantified through the interquartile range (IQR): $\mathrm{IQR}=\mathrm{Q} 3-\mathrm{Q} 1$, where Q1 and Q3 are respectively the first and the third quartiles of the distribution. Both metrics are defined in such a way that a large value indicates higher predictability. We chose to use these two definitions as recent studies have argued that SNR is a better measure of predictability than the spread (e.g., Larson and Kirtman 2019; Larson and Pegion 2020).

\section{Model evaluation}

Figure 1 provides a brief comparison of ENSO simulated in CNRM-CM5 and other climate models with observations. ENSO amplitude and seasonality are relatively well simulated in CNRM-CM5 (respectively $1.1^{\circ} \mathrm{C}$ and 1.7 in the model; $1.2^{\circ} \mathrm{C}$ and 1.9 in the observations), as it is among the top $10 \%$ of
CMIP models for both. The asymmetries between El Niño and La Niña in terms of amplitude, duration, and transition are underestimated by CNRM-CM5 (respectively $0.4^{\circ} \mathrm{C}, 1.0$, and 1.5 in the model; $1.0^{\circ} \mathrm{C}, 1.3$, and 2.8 in the observations) but it is still among the top 50\% of CMIP models for the three asymmetries. The wind stress feedback is underestimated by $40 \%$ in CNRM-CM5, while the heat flux feedback is very close to the observed estimate. This deviates from what generally happens in the CMIP database, where there is an error compensation between these two underestimated feedbacks (Bayr et al. 2019). The realistic ENSO amplitude in CNRM-CM5 may rather result from an error compensation between the underestimated wind stress and overestimated thermocline feedback (by 30\%). Despite these errors, the model CNRM-CM5 is among the top $30 \%$ of CMIP models for the three feedbacks.

Given the importance of WWE for ENSO dynamics and predictability, we also evaluate how they are reproduced in the CNRM-CM5 model. Figure 2 provides a quantitative evaluation of WWE dependence on ENSO phase. As already discussed in Puy et al. (2019), there is an $\sim 0.7$ correlation between the March-December integrated WEI (a proxy of the oceanic response) and the NDJ N3 SSTA in observations and the CNRM-CM5 model (Figs. 2a,b). The model reproduces the observed tendency to have more frequent and/or intense WWEs during El Niño than during La Niña events (not shown). Previous studies have related this intensification of WWE during El Niño events to the displacements of the WPEE (e.g., Puy et al. 2016). Figure 2c shows the monthly mean WEI for a given WPEE location and indicates that WWEs become progressively more frequent and/or intense as the WPEE moves eastward in observations and CNRM-CM5. A more detailed evaluation of wind events in CNRM-CM5 can be found in Puy (2016).

In this study, we want to investigate the asymmetric relation between the oceanic preconditioning in boreal autumn and ENSO peak amplitude one year later discussed by Planton et al. (2018). The CNRM-CM5 model captures the tendency for El Niño events to be preceded by positive T300 ${ }_{W} \mathrm{~A}$ and $\mathrm{La}$ Niña events to be preceded by negative T300 ${ }_{W}$ A (e.g., Meinen and McPhaden 2000; Planton et al. 2018; Izumo et al. 2019) 10 to 16 months before the ENSO peak (correlations around 0.5; Fig. 3a; note that while $\mathrm{T} 300_{W} \mathrm{~A}$ is the best long-term precursor of ENSO, it only explains $15 \%-35 \%$ of its variance at such long lead times). As shown by the transition asymmetry metric, CNRM-CM5 is, however, too biennial, resulting in an overestimation of the correlation between SSTA and ENSO amplitude 1 year later $(-0.4$ in CNRM-CM5 and -0.1 in the observations, outside observational uncertainties). Figure $3 \mathrm{~b}$ reproduces the observed diagnostic of the relationship between boreal autumn T300 ${ }_{W} \mathrm{~A}$ and ENSO event one year later discussed in Planton et al. (2018). This suggests an asymmetrical relationship, with an almost linear relation between discharged $\mathrm{T} 300_{W} \mathrm{~A}$ and La Niña amplitude one year later, but a wide range of outcomes (ranging from moderate La Niña to extreme El Niño) after recharged $\mathrm{T} 300_{W} \mathrm{~A}$.

The CNRM-CM5 model reproduces essential ENSO properties (amplitude and seasonality), asymmetries, and feedbacks reasonably well. In this regard, it ranks among the best of 

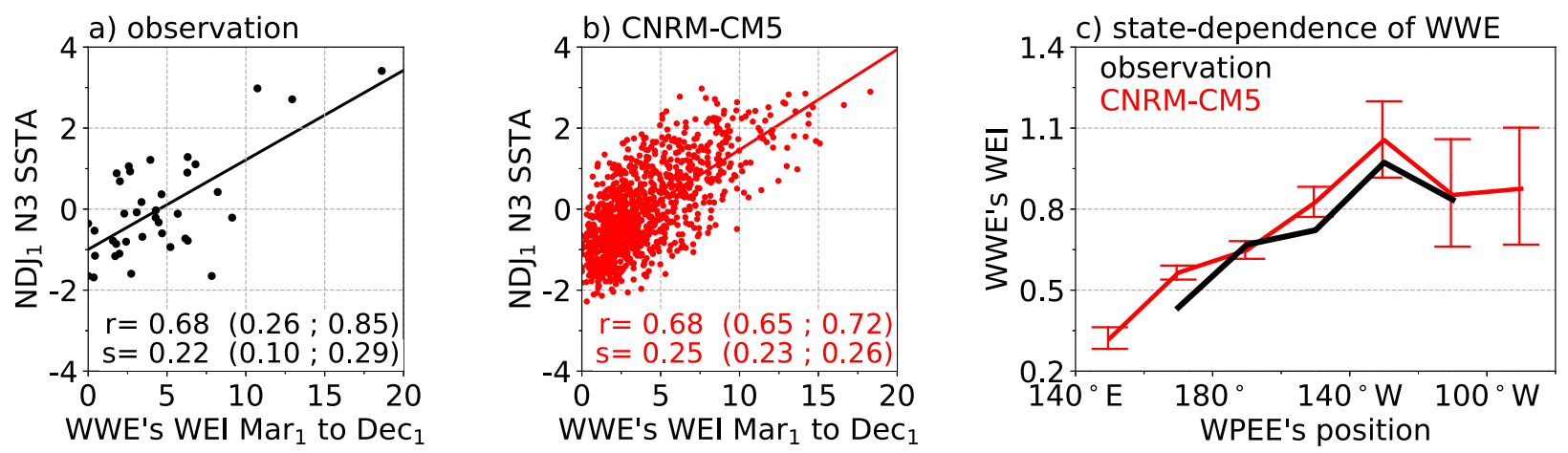

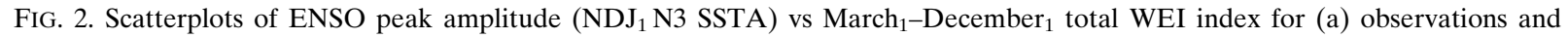
(b) CNRM-CM5. Solid lines represent the linear regression slopes. The corresponding correlation $r$ and regression slope $s$ are indicated at the bottom of each panel, with the $95 \%$ confidence interval in parentheses. (c) WEI as a function of the WPEE position for observations (black) and CNRM-CM5 (red), indicative of the state-dependent component of WWE. The WEI is summed across longitudes for each month and averaged for a given position of the WPEE $\left(20^{\circ}\right.$ bins $)$. Red error bars indicate the $95 \%$ confidence interval computed with CNRM-CM5 (the confidence interval is larger for the observations and for readability is not plotted).

CMIP models (Fig. 1; see also Bellenger et al. 2014; Planton et al. 2020). Of particular importance for this study, it reproduces the asymmetrical boreal autumn $\mathrm{T} 300_{W} \mathrm{~A}$ lead relation with ENSO 1 year later, and the ENSO state dependence of WWE. This indicates that this model is well suited to investigate the asymmetry in ENSO predictability. It is, however, important to keep in mind that this model underestimates observed ENSO asymmetries and the wind stress feedback and overestimates the frequency of the transition from La Niña events to El Niño events. The potential impacts of these deficiencies on our results are discussed in section 6 .

\section{Results}

The goals of this study are 1) to confirm using a dynamical framework the statistical results of Planton et al. (2018) indicating that a discharged western Pacific is more likely to lead to a La Niña one year after than a recharged western Pacific to an El Niño and 2) to propose a mechanism explaining this asymmetry. To that end, we designed ENSO ensemble forecast experiments in a perfect model setting where the predictability is only limited by the chaotic growth of infinitesimal initial errors. Below, we first describe how we selected the set of initial states for the ensemble experiments and then show that experiments starting from discharged states have a more predictable ENSO evolution. We then propose a mechanism that explains this asymmetry in predictability.

\section{a. Ensemble experiments design and results}

The correlation between $\mathrm{T} 300_{W} \mathrm{~A}$ and ENSO amplitude at its peak (NDJ N3 SSTA) is maximum when T300 ${ }_{W} \mathrm{~A}$ leads by about 1 year in the CNRM-CM5 model (Fig. 3a), in broad agreement with observations (e.g., Planton et al. 2018; Izumo et al. 2019). We hence decided to start our set of ensemble experiments on 1 November, from either recharged or discharged $\mathrm{T} 300_{W} \mathrm{~A}$. In observations, there is a tendency for recharged $\mathrm{T} 300_{W} \mathrm{~A}$ to occur during La Niña, and discharged during El Niño, but this is not a one-to-one relation (e.g.,
Meinen and McPhaden 2000). Figure 3c provides a scatterplot of October (monthly average) N3 SSTA (i.e., ENSO state) versus October $\mathrm{T} 300_{W} \mathrm{~A}$ (i.e., ENSO preconditioning). As expected, the preconditioning is anticorrelated $(r=-0.76)$ with the ENSO state, with a tendency for western Pacific discharge at the peak of El Niño and recharge for La Niña. A recharged $\mathrm{T} 300_{W} \mathrm{~A}$ (normalized $\mathrm{T} 300_{W} \mathrm{~A}>0.5$ ) can, however, be associated with different ENSO conditions: extreme La Niña, moderate La Niña, neutral state, and a few rare instances of weak El Niño (Fig. 3c). For a discharged T300 ${ }_{W} \mathrm{~A}$ (normalized T300 $\left.{ }_{W} \mathrm{~A}<-0.5\right)$, the Pacific can be in a neutral ENSO, moderate El Niño, and an extreme El Niño state, which is associated with an extreme discharge (that we define as normalized $\left.\mathrm{T} 300_{W} \mathrm{~A}<-1.5\right)$. The observations display very similar features to those in the model (not shown). Our goal is to define two sets of contrasting initial states that are characteristic of recharged and discharged $\mathrm{T} 300_{W} \mathrm{~A}$. Figure $3 \mathrm{c}$ indicates that this broadly corresponds to six situations in total: three recharged (extreme La Niña, La Niña, and neutral) and three discharged (neutral, El Niño, and extreme El Niño, also corresponding to an extreme discharge) states. There are many possible initial conditions from our 1007-yr-long control simulation for each of those six cases (delineated by dashed lines on Fig. $3 c$ that are based on the $0.5 \times$ STD and $1.5 \times$ STD thresholds for T300 ${ }_{W} \mathrm{~A}$ and N3 SSTA, where STD is the standard deviation). In each case, we picked the initial condition that was closest to the centroid of the distribution within the box. We then pair the chosen recharged and discharged restarts as follows:

- neutral ENSO states, hereinafter $\mathrm{NEU}_{R}$ (R for recharged; dark-red cross) and $\mathrm{NEU}_{D}$ (D for discharged; dark-turquoise cross),

- moderate El Niño/La Niña states, hereinafter $\mathrm{MOD}_{R}$ (darkred left-pointing triangle) and $\mathrm{MOD}_{D}$ (dark-turquoise rightpointing triangle), and

- extreme El Niño/La Niña states, hereinafter $\mathrm{EXT}_{R}$ (darkred upward-pointing triangle) and $\mathrm{EXT}_{D}$ (dark-turquoise downward-pointing triangle). 

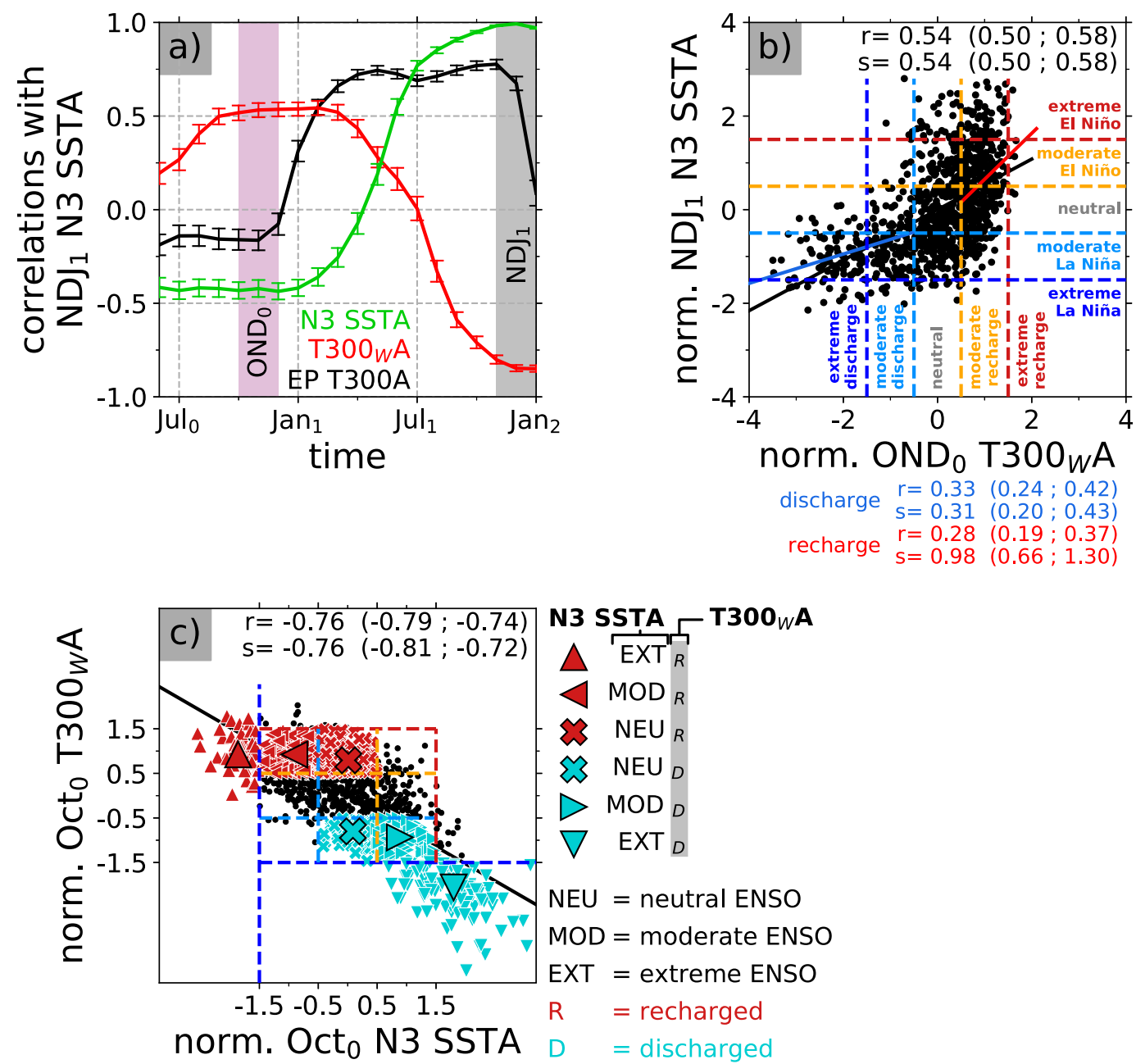

FIG. 3. (a) Lead correlations between $\mathrm{T} 300_{W} \mathrm{~A}$ (red), anomalies of $\mathrm{T} 300$ averaged over the entire equatorial Pacific (EP T300A; black), N3 SSTA (green), and NDJ (gray shading) N3 SSTA. Error bars indicate the 95\% confidence interval. (b) Scatterplot of normalized $\mathrm{NDJ}_{1}$ [gray shading in (a)] N3 SSTA vs normalized OND $_{0}$ [purple shading in (a)] T300 ${ }_{W}$ A. (c) Scatterplot of normalized October $_{0}$ T300 $_{W}$ A vs normalized October $_{0}$ N3 SSTA. This figure is used is to select initial states for our ensemble predictability experiments. In (b) and (c), the dashed lines indicate the $-1.5 \times$ STD (deep blue; limit between extreme and moderate La Niña/discharges), $-0.5 \times$ STD (light blue; limit between moderate and neutral La Niña/discharges), $0.5 \times \mathrm{STD}$ (orange; limit between neutral and moderate El Niño/recharge), and $1.5 \times \mathrm{STD}$ (red; limit between moderate and extreme El Niño/recharge) thresholds. In (b) and (c), the black solid line represents the linear regression slope, and the corresponding $r$ and $s$ are indicated at the top of each panel, with the $95 \%$ confidence interval within brackets. In (b), the blue and red solid lines represent the linear regression slopes computed for discharged and recharged states, and the corresponding $r$ and $s$ are indicated under the panel, with the 95\% confidence interval within parentheses. The CNRMCM5 1007-yr-long control experiment is used for this figure.

In the "extreme" experiments $\left(\mathrm{EXT}_{R}\right.$ and $\left.\mathrm{EXT}_{D}\right)$, the recharged/ discharged states are not symmetrical because extreme El Niño events generally correspond to extreme discharges in the model, whereas extreme La Niña events generally correspond to more moderate recharges, as in observations and most CMIP5 models (Planton et al. 2018).

Figure 4 illustrates the evolution of N3 SSTA in these six ensemble experiments (Figs. 4a,b,f,g,k,l), including the statistics of NDJ N3 SSTA after one year (Figs. 4c,h,m) and the associated predictability metrics (Figs. 4d,e,i,j,n,o). In all experiments, the ensemble spread initially increases slowly and generally picks up during or after boreal summer. The maximum spread is reached during boreal winter $\left(\mathrm{NDJ}_{1}\right.$; gray shading in Figs. 4a,b,f,g,k,1). Experiments starting from a recharged state in November often evolve into a neutral or El Niño state after one year $(>77 \%$ of the cases, whatever the initial ENSO phase), whereas the experiments starting from a discharge preferentially mostly yield a neutral or La Niña state ( $>84 \%$ of the cases; Figs. 4c,h,m). The experiments starting from extreme ENSO phases do not mirror each other in terms 


\section{recharged}

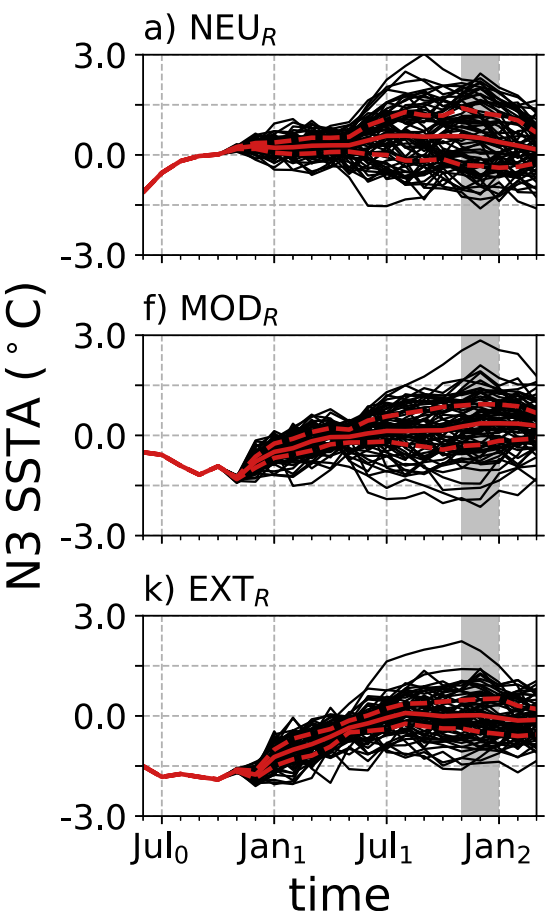

discharged

b) $\mathrm{NEU}_{D}$

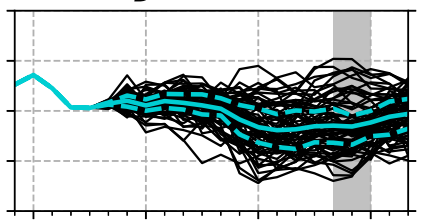

g) $M O D_{D}$

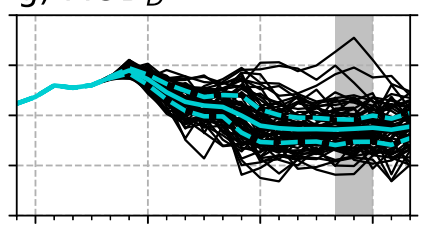

I) $\mathrm{EXT}_{D}$

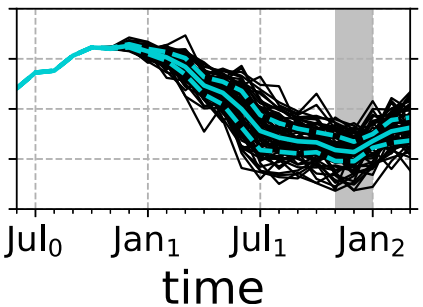

c)

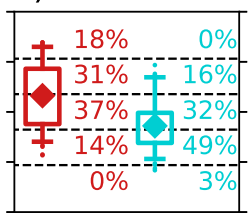

h)

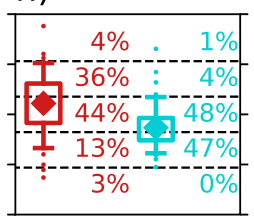

m)

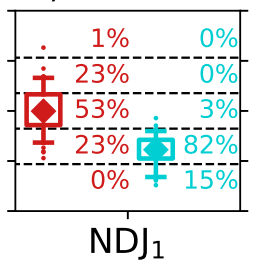

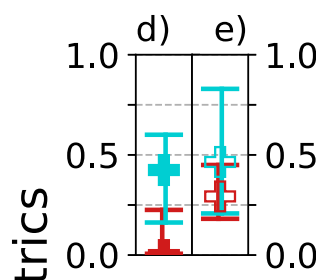
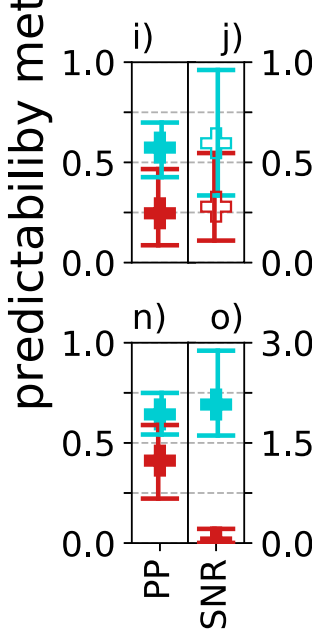

FIG. 4. Evolution of ensemble experiments starting on 1 November $_{0}$ from recharged $(R$; dark red) and discharged ( $D$; dark turquoise) T300 $W \mathrm{~A}$ and (top) neutral, (middle) moderate, and (bottom) extreme ENSO initial states. (a),(b),(f),(g),(k),(l) Evolution of N3 SSTA. Dashed lines indicate the 25th and 75th percentiles, and the solid line indicates the mean. Gray shading indicates $\mathrm{NDJ}_{1}$, the season of the ENSO peak. (c),(h),(m) Distribution of ENSO peak amplitudes (NDJ ${ }_{1}$ N3 SSTA). Whiskers extend to the 5th and 95th percentiles, boxes encompass the 25 th and 75 th percentiles [the difference between these two is the interquartile range (IQR)], diamonds mark the mean, and dots indicate members that fall outside the whiskers. From bottom to top, the numbers respectively indicate the percentage of extreme La Niña, moderate La Niña, neutral, moderate El Niño, and extreme El Niño events. Also shown are predictability metrics for ENSO

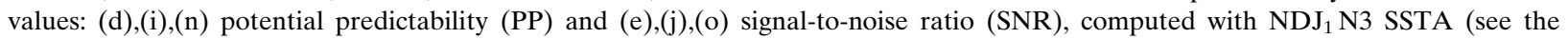
appendix for the definition of these metrics). Error bars indicate the $95 \%$ confidence interval. Filled symbols indicate significantly different values at the $95 \%$ confidence level between the recharged and discharged experiments.

of mean SSTA evolution: the one starting from a recharge (extreme La Niña) is most likely to evolve into a neutral state $(53 \%)$, while the experiment starting from a discharge (extreme El Niño) is most likely to evolve into a moderate or extreme La Niña (97\%). For each pair of experiments, the N3 SSTA distribution at the ENSO peak one year later is systematically wider in the recharged experiments than in the discharged experiments (see box-and-whisker plots in Figs. 4c,h,m). This translates into differences in the predictability metrics between recharged and discharged experiments. For each pair of experiments, the potential predictability (PP; Figs. 4d,i,n) is significantly smaller in the recharged than in the discharged experiments, at the $95 \%$ significance level. This indicates that recharged states lead to a broader ENSO distribution 1 year later than discharged states. This measure of predictability, however, does not take the amplitude of the ENSO signal into account.

In section $4 \mathrm{~b}$, we first compare the evolution of experiments starting from ENSO-neutral initial states $\left(\mathrm{NEU}_{R}\right.$ and $\left.\mathrm{NEU}_{D}\right)$. On this basis, we propose a physical interpretation of why experiments starting from a discharged state are more predictable. In section $4 \mathrm{c}$, we show that the same mechanism applies for ENSO transitions (i.e., MOD and EXT experiments) and generalize these results to experiments initialized with a broader set of initial conditions.

\section{b. Neutral initial ENSO conditions}

Figures $5 \mathrm{a}$ and $5 \mathrm{~b}$ illustrate the evolution of the equatorial SSTA (shading), T300A (black contours), WPEE (gray lines), and WWE activity (red dots) ensemble mean, and Figs. 5c and $5 \mathrm{~d}$ show the spread in the $\mathrm{NEU}_{R}$ (Figs. 5a,c) and $\mathrm{NEU}_{D}$ (Figs. 5b,d) experiments. Figure 6 further compares the evolution of essential variables and feedbacks for this pair of experiments. $\mathrm{NEU}_{R}$ and $\mathrm{NEU}_{D}$ (Figs. 5a,b and 6a) both start from near-neutral SSTA in the $\mathrm{N} 3$ region $\left(\sim 0.2^{\circ} \mathrm{C}\right.$ in $\left.\mathrm{NDJ}_{0}\right)$. The eastern equatorial Pacific ensemble mean SSTA remain stable and similar in the two experiments until boreal spring $\left(\mathrm{MAM}_{1}\right)$. In late boreal spring and early summer, the N3 region anomalously warms in $\mathrm{NEU}_{R}$ and anomalously cools in $\mathrm{NEU}_{D}$. The classical explanation of the emergence of these SSTA in the recharge oscillator framework is that anomalous western Pacific recharge favors the development of positive SSTA, and anomalous discharge favors the development of 
Mean

a) $\mathrm{NEU}_{R}$

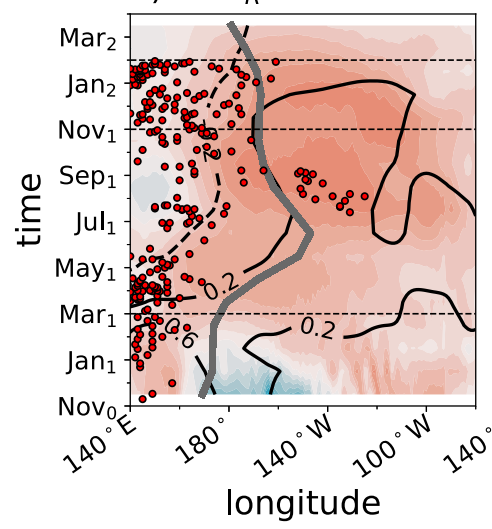

- T300A $\left({ }^{\circ} \mathrm{C}\right)$
WWE $($ WEI $>1)$ b) $\mathrm{NEU}_{D}$

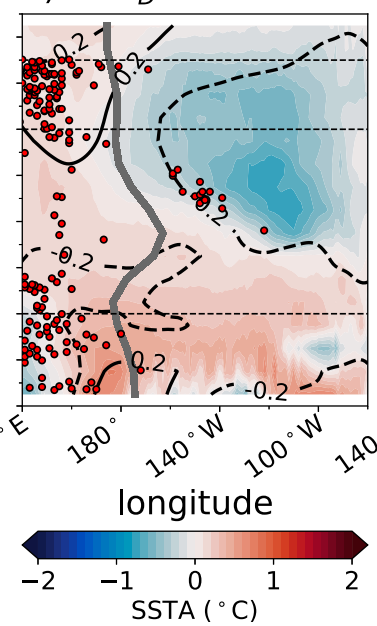

Spread

c) $\mathrm{NEU}_{R}$

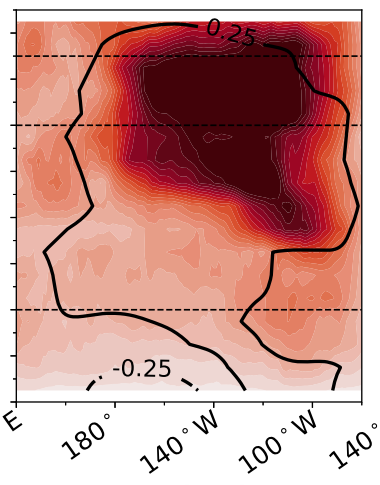

longitude

- mean SSTA $\left({ }^{\circ} \mathrm{C}\right)$ d) $\mathrm{NEU}_{D}$

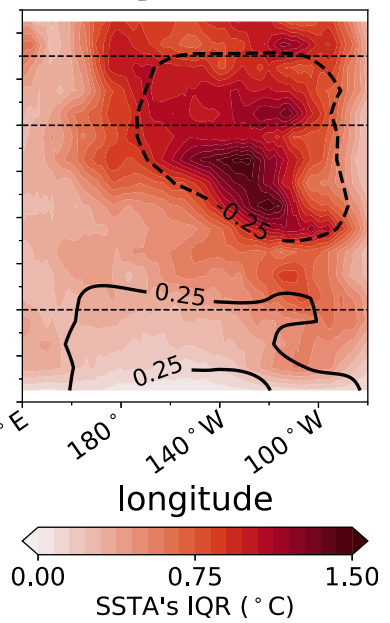

FIG. 5. Time section of the 70-member ensemble experiments starting on 1 November $_{0}$ from neutral ENSO states, with either a recharged $\left(\mathrm{NEU}_{R}\right)$ or discharged $\left(\mathrm{NEU}_{D}\right) \mathrm{T} 300_{W} \mathrm{~A}$. (a), (b) $5^{\circ} \mathrm{N}-5^{\circ} \mathrm{S}$ meridional averaged ensemble mean SSTA (shading; $\left.{ }^{\circ} \mathrm{C}\right)$ and T300A (black contours; ${ }^{\circ} \mathrm{C}$ ), WPEE (gray line), and WWE from all 70 members with a WEI index above 1 (red dots). (c),(d) The $5^{\circ} \mathrm{N}-5^{\circ} \mathrm{S}$ meridional averaged ensemble IQR of SSTA (shading; ${ }^{\circ} \mathrm{C}$ ) and ensemble mean SSTA (black contours; ${ }^{\circ} \mathrm{C}$ ). $\mathrm{The} \mathrm{NEU}_{R}$ and $\mathrm{NEU}_{D}$ experiments correspond to initial states respectively marked by the dark red and dark turquoise crosses on Fig. 3c. Data are smoothed with an $11^{\circ}$ and 3-months triangular-weighted running average prior to plotting.

negative SSTA, through the thermocline and zonal advective feedbacks (e.g., Jin and An 1999). The thermocline feedback indeed strongly intensifies after boreal spring in both experiments (Fig. 6e), allowing subsurface thermal anomalies to connect with the surface, and explaining the progressive warming of $\mathrm{NEU}_{R}$ and cooling of $\mathrm{NEU}_{D}$. We did not diagnose the zonal advective feedback, but it probably also contributes to the differential heating in the central Pacific between the two experiments, as underlined by the much stronger eastward displacement of the WPEE in $\mathrm{NEU}_{R}$ during boreal spring (Fig. 6b). These contrasting ensemble mean SSTA after early summer in the two experiments are associated with marked differences in the ENSO spread. The SSTA ensemble spread is similar in $\mathrm{NEU}_{R}$ and in $\mathrm{NEU}_{D}$ up to mid boreal summer but then it increases much more in $\mathrm{NEU}_{R}$ than in $\mathrm{NEU}_{D}$ (Figs. $5 \mathrm{c}, \mathrm{d}$ and $6 \mathrm{a})$. At the end of the year, the SSTA ensemble spread of $\mathrm{NEU}_{R}$ is almost twice as large as that of $\mathrm{NEU}_{D}\left(1.7^{\circ}\right.$ and $0.9^{\circ} \mathrm{C}$ respectively). At the time of the ENSO peak, $\mathrm{NEU}_{R}$ has mostly evolved into neutral $(37 \%)$ or El Niño (49\%, including moderate and extreme events) states (Fig. 4c), while $\mathrm{NEU}_{D}$ mostly yields neutral $(32 \%)$ or La Niña $(52 \%$, including moderate and extreme events) states (Fig. 4c). Below, we first comment on the differences in ENSO feedbacks and WWE ENSO state dependence between $\mathrm{NEU}_{R}$ and $\mathrm{NEU}_{D}$, and then propose a mechanism for the enhanced spread in $\mathrm{NEU}_{R}$.

ENSO feedbacks play an essential role in ENSO growth. We thus start by discussing differences in essential ENSO feedbacks between $\mathrm{NEU}_{R}$ and $\mathrm{NEU}_{D}$. Figure $6 \mathrm{~d}$ indicates that the wind stress feedback is larger in $\mathrm{NEU}_{R}$ than in $\mathrm{NEU}_{D}$ during boreal spring to autumn, this difference being significant at the $95 \%$ confidence level only at the end of the calendar year. This larger wind stress feedback is likely due to the warmer ensemble mean SSTA in $\mathrm{NEU}_{R}$ after boreal spring (Figs. 5c, d and $6 a, b)$. Previous studies have indeed underlined that the existence of a threshold for deep atmospheric convection in the tropics (e.g., Gadgil et al. 1984; Graham and Barnett 1987) induces a larger convective and wind stress response for positive than for negative SSTA (e.g., Lloyd et al. 2009; Frauen and Dommenget 2010; Choi et al. 2013; Dommenget et al. 2013; Im et al. 2015; Takahashi and Dewitte 2016). The negative heat flux feedback is also stronger (i.e., more negative) in $\mathrm{NEU}_{R}$ from the end of the summer season (Fig. 6), this difference being significant at the $95 \%$ confidence level at the end of the calendar year as for the wind stress feedback. This larger heat flux feedback in $\mathrm{NEU}_{R}$ can also be related to the nonlinearity of the convective response to surface temperature. The thermocline feedback is very similar between the two experiments until late boreal autumn, when it briefly becomes slightly weaker in $\mathrm{NEU}_{R}$ (Fig. 6e). We did not attempt to estimate the overall Bjerknes feedback, which is a complex balance between many terms (e.g., Jin et al. 2006). The effect of the stronger wind stress feedback in $\mathrm{NEU}_{R}$ is, however, probably partially offset by the stronger stabilizing heat flux feedback. In addition, these differences in ENSO feedback only become statistically significant near the end of the calendar year (Figs. 6d-f), once the spread of the $\mathrm{NEU}_{R}$ experiment has already become larger (Fig. 6a). While the difference in those low-frequency feedbacks may contribute to the reduced predictability in the $\mathrm{NEU}_{R}$ experiment, especially toward the end of the year, it is thus most likely not the primary cause.

WWEs also play a key role in the growth of ENSO and Jin et al. (2007) demonstrated that their state dependence could 

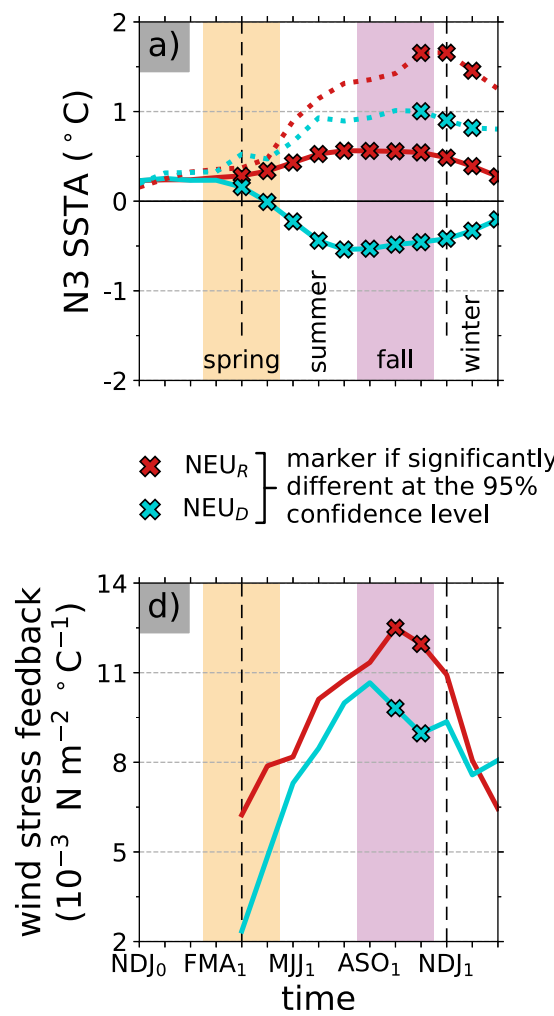

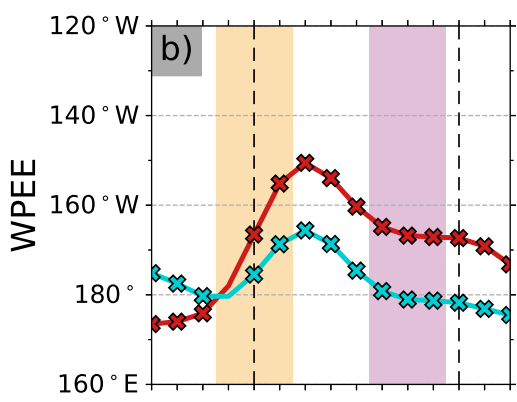

$$
\begin{aligned}
& \text { NEU }=\text { neutral ENSO } \\
& R=\text { recharged } \\
& D=\text { discharged }
\end{aligned}
$$

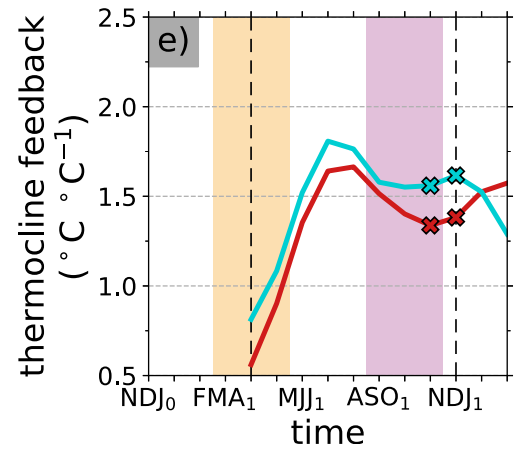

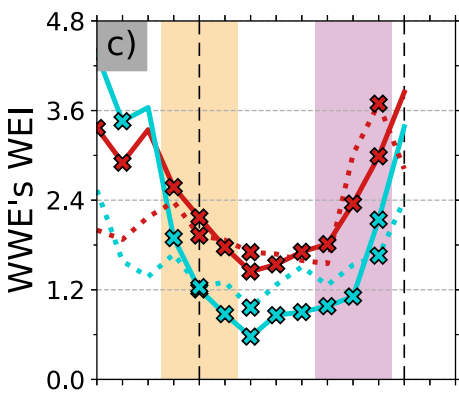

- mean

.... IQR

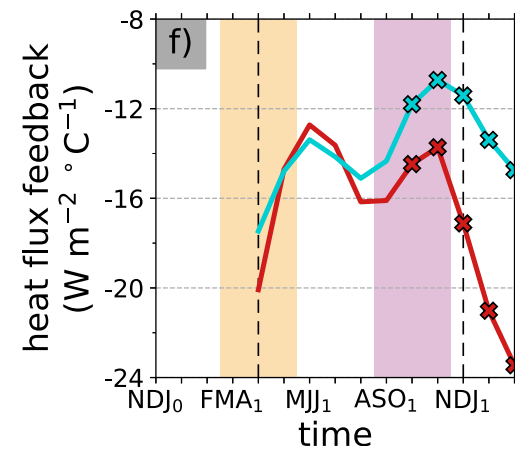

FIG. 6. Evolution of the key ENSO variables and feedbacks in the 70-member ensemble experiments starting on 1 November $_{0}$ from a neutral ENSO state, with either a recharged ( $\mathrm{NEU}_{R}$; dark red) or discharged ( $\mathrm{NEU}_{D}$; dark turquoise) T300 ${ }_{W} \mathrm{~A}$. Ensemble mean (solid line) of (a) N3 SSTA $\left({ }^{\circ} \mathrm{C}\right.$ ), (b) position of the WPEE, (c) WEI index (seasonally integrated across longitudes), (d) wind stress feedback $\left(10^{-3} \mathrm{~N} \mathrm{~m}^{-2}{ }^{\circ} \mathrm{C}^{-1}\right)$, (e) thermocline feedback $\left({ }^{\circ} \mathrm{C}^{\circ} \mathrm{C}^{-1}\right)$, and (f) heat flux feedback $\left(\mathrm{W} \mathrm{m}^{-2}{ }^{\circ} \mathrm{C}^{-1}\right)$. The IQR of N3 SSTA and WEI are respectively also plotted as dotted lines in (a) and (c) The $\mathrm{NEU}_{R}$ and $\mathrm{NEU}_{D}$ experiments respectively correspond to initial states marked by the dark red and dark turquoise crosses in Fig. 3c. Crosses indicate significantly different values between $\mathrm{NEU}_{R}$ and NEU $\mathrm{N}_{D}$ experiments, at the $95 \%$ confidence level.

lead to a more predictable cold ENSO phase in the recharge oscillator conceptual model. To assess their impact, we use the WEI or "wind event intensity" index, which is a proxy of the oceanic impact of WWEs (see methods section). The WEI is significantly higher in $\mathrm{NEU}_{R}$ very early in the calendar year, namely from boreal spring onward (Fig. 6c). This increase of the WWE activity can be related to a more eastward WPEE in $\mathrm{NEU}_{R}$ (Figs. 5a,b and 6b). The WEI is not only larger in $\mathrm{NEU}_{R}$ ensemble mean, but also more variable between members, especially during the event onset in late boreal spring and early summer [see IQR in Fig. 6c (dashed line)]. Figure 2c indeed shows that the WEI not only becomes larger when the WPEE moves eastward, but also more variable (see the red error bars, which measure the WEI stochasticity), leading to more spread in the N3 SSTA (Fig. 6a). WWE ENSO state dependence is thus a likely explanation of the reduced predictability in $\mathrm{NEU}_{R}$.

To summarize, the thermocline and zonal advective feedbacks yield an anomalously warm N3 SSTA $\left(0.5^{\circ} \mathrm{C}\right)$ and eastward WPEE in the $\mathrm{NEU}_{R}$ experiment from boreal spring onward while the feedbacks produce anomalously cold SST $\left(-0.5^{\circ} \mathrm{C}\right)$ and westward WPEE in the $\mathrm{NEU}_{D}$ experiment. The ENSO state dependence of WWE in our model (Fig. 2c) then leads to more active WWE in the ensemble mean and more
WWE stochasticity across the members in $\mathrm{NEU}_{R}$, in agreement with results found in the recharge oscillator model (Jin et al. 2007). Warmer surface temperatures also induce a larger wind stress feedback in the recharged experiment relative to the discharged experiment. However, the wind stress feedback only becomes significantly larger in $\mathrm{NEU}_{R}$ during boreal autumn and early winter, after the increase in spread. In addition, at the same time the heat flux feedback is more negative in $\mathrm{NEU}_{R}$ (implying greater damping), offsetting the wind stress feedback change. For those two reasons, the most likely mechanism that accounts for the less-predictable evolution in the $\mathrm{NEU}_{R}$ relative to the $\mathrm{NEU}_{D}$ experiment is thus associated with the ENSO state dependence of WWE. We cannot exclude the possibility, however, that the stronger wind stress feedback induced by warmer surface temperatures in the recharged experiment also contributes. We will come back to this point in section 6 .

\section{c. El Niño/La Niña initial conditions and generalization}

In section $4 \mathrm{~b}$, we investigated the mechanisms that could explain the weaker ENSO predictability after recharged states than discharged states, in the case of ENSO-neutral initial conditions. Here, we show that the same mechanisms explain 

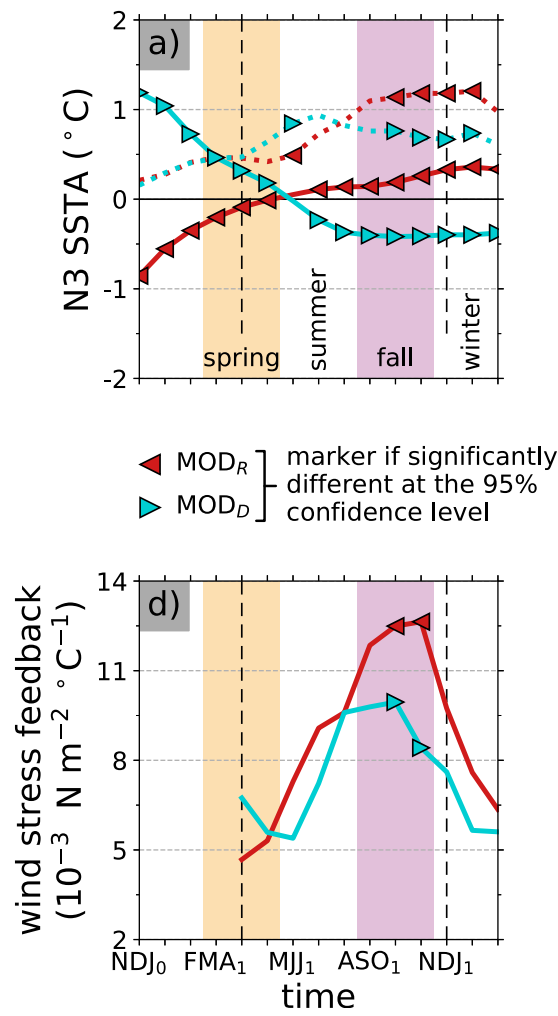

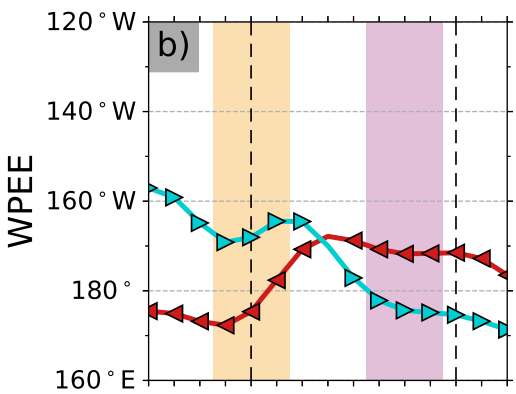

$$
\begin{aligned}
& \text { MOD = moderate ENSO } \\
& R=\text { recharged } \\
& D=\text { discharged }
\end{aligned}
$$

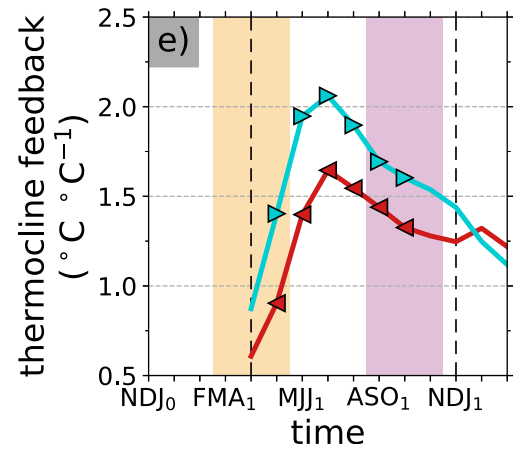

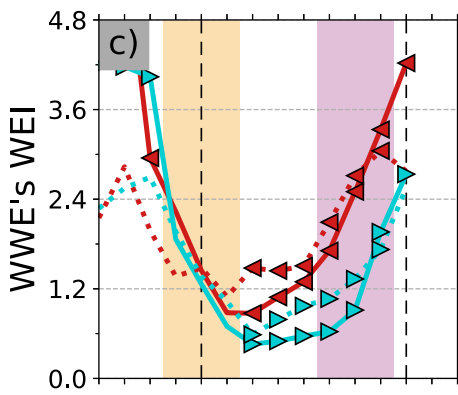

- mean

.... IQR

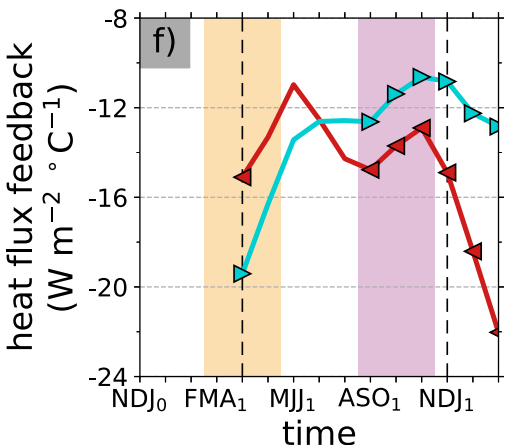

FIG. 7. As in Fig. 6, but for 70-member ensemble experiments starting on 1 November $_{0}$ from either a moderate La Niña recharged $\mathrm{T} 300_{W} \mathrm{~A}\left(\mathrm{MOD}_{R}\right.$; dark red) or a moderate El Niño discharged T300 ${ }_{W} \mathrm{~A}\left(\mathrm{MOD}_{D}\right.$; dark turquoise). The MOD $\mathrm{M}_{R}$ and $\mathrm{MOD}_{D}$ experiments respectively correspond to initial states marked by the dark-red left-pointing triangles and dark-turquoise right-pointing triangles in Fig. 3c.

the weaker predictability associated with recharged initial states, in the case of ENSO phase transitions-that is, after moderate $\left(\mathrm{MOD}_{R}\right.$ vs $\mathrm{MOD}_{D}$; Fig. 7) and extreme $\left(\mathrm{EXT}_{R}\right.$ vs $\mathrm{EXT}_{D}$; Fig. 8) ENSO. In both cases, warmer ensemble mean N3 SSTA appears from boreal summer onward in the recharged experiments (Figs. 7a and 8a), probably due to the thermocline and zonal advective feedbacks (see WPEE displacement in Figs. $7 \mathrm{~b}$ and $8 \mathrm{~b})\left(\mathrm{MOD}_{R}\right.$ and $\left.\mathrm{EXT}_{R}\right)$. As a result, similar to the NEU experiments, the ensemble mean WEI and its spread are significantly larger from early boreal summer to winter in the recharged than in the discharged experiments (Figs. 7c and 8c). Consistent with Jin et al.'s (2007) results, this is probably the main factor that contributes to lower predictability in recharged experiments. The wind stress feedback in the recharged relative to the discharged experiments is significantly larger during boreal autumn in the MOD experiments (Fig. 7d), and almost never significantly larger in the EXT experiments (Fig. 8d; difference significant during $\mathrm{NDJ}_{1}$ ). Its effect on the Bjerknes feedback is also partially offset by a significantly stronger negative heat flux feedback in the recharged experiments after boreal summer (Figs. 7f and 8f), as was the case in the NEU experiments. One notable difference with the NEU experiments is that there is a statistically significant difference in the thermocline feedback in the MOD and EXT experiments from boreal summer onward (Figs. 7e and $8 \mathrm{e}$ ). However, as for the heat flux feedback change, it goes in the "wrong direction" as the stronger thermocline feedback in the discharged experiments would tend to enhance the Bjerknes feedback (Jin et al. 2006), making the coupled system more unstable, and enhancing the spread (which could explain why the spread is larger in the discharged experiments until late summer, before the situation reverses). Overall, the clearest factor to explain the weaker predictability of recharged states during ENSO phase transitions is thus the ENSO state dependence of WWE, but the wind stress feedback may also play a role in MOD experiments. The processes highlighted here are in general agreement with Dommenget el al. (2013), who showed that El Niño events are mostly wind driven while La Niña events are thermocline driven.

The analysis of this set of six ensemble experiments has thus highlighted 1) that western Pacific recharged states lead to less ENSO predictability than discharged states, irrespective of the previous ENSO state, and 2) that this weaker predictability is most likely caused by the ENSO state dependence of WWEs (i.e., the tendency of WWEs to become more numerous and more stochastic as the Pacific warms) and may be enhanced by the wind stress feedback. Now we show that our physical interpretation is not limited to the six specific initial states we considered for our ensemble experiments but can apply to a more general context. To this end, we introduce eight additional 

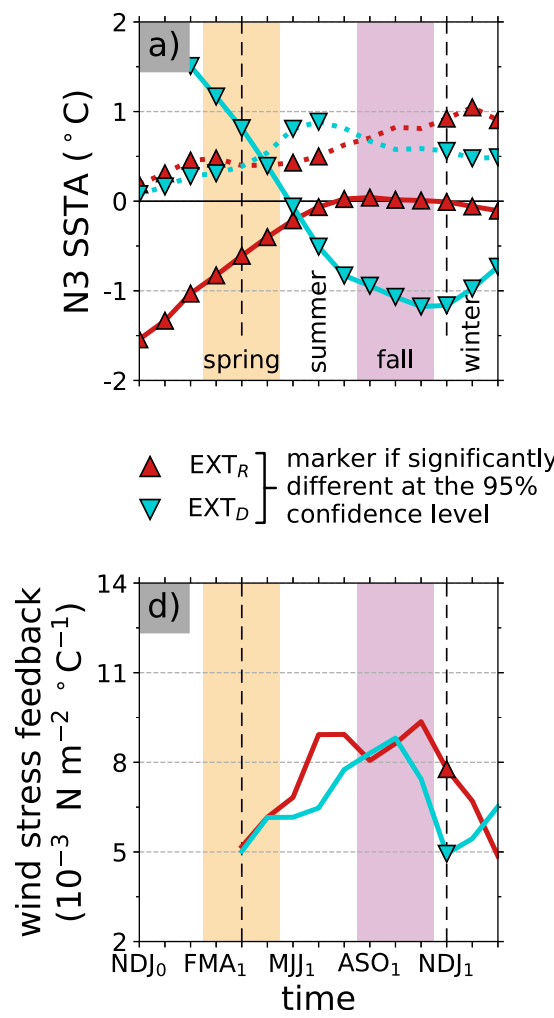

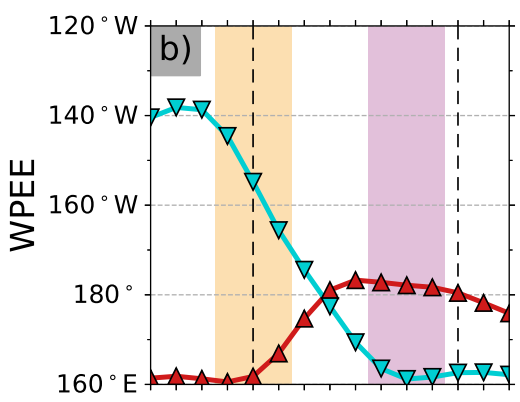

$$
\begin{aligned}
& \text { EXT = extreme ENSO } \\
& R=\text { recharged } \\
& D=\text { discharged }
\end{aligned}
$$

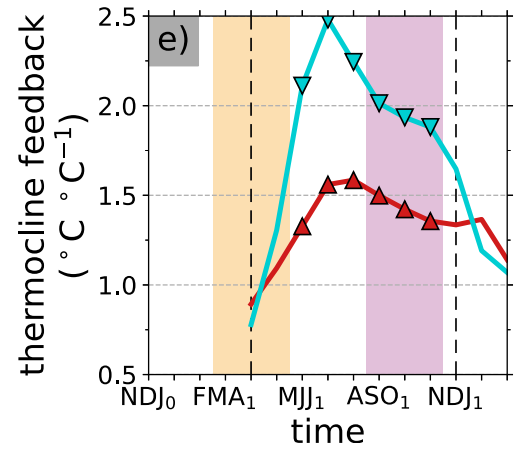

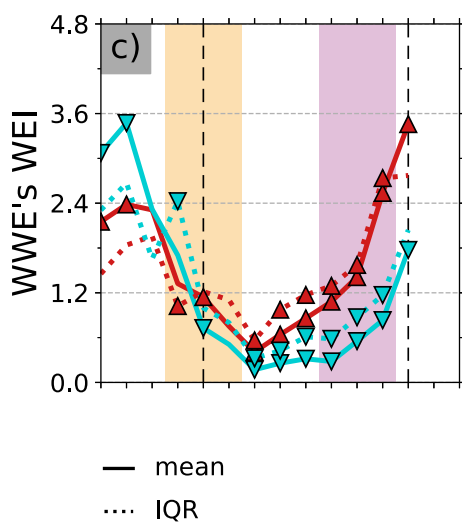

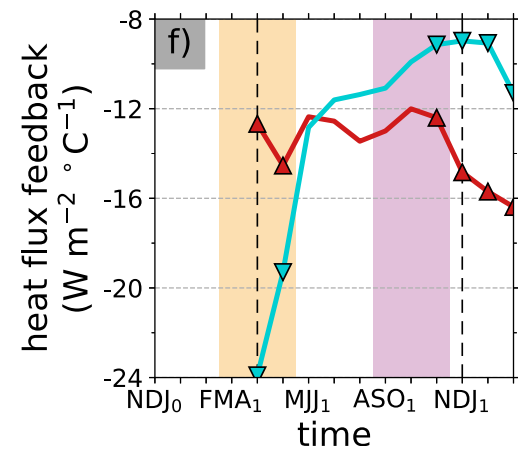

FIG. 8. As in Fig. 6, but for 70-member ensemble experiments starting on 1 November $_{0}$ from either an extreme La Niña recharged T300 ${ }_{W} \mathrm{~A}$ $\left(\mathrm{EXT}_{R}\right.$; dark red) or an extreme El Niño discharged $\mathrm{T}_{300} \mathrm{~A}\left(\mathrm{EXT}_{D}\right.$; dark turquoise). The $\mathrm{EXT}_{R}$ and $\mathrm{EXT}_{D}$ experiments respectively correspond to initial states marked by the dark-red upward-pointing and dark-turquoise downward-pointing triangles in Fig. $3 \mathrm{c}$.

ensemble experiments, with initial states designed to cover a broader spectrum of initial conditions (Fig. 9a). This extra set of experiments includes three experiments starting from a neutral T300 ${ }_{W} \mathrm{~A}$ (during either a moderate La Niña, neutral state, or moderate El Niño), two experiments with an intermediate T300 ${ }_{W} \mathrm{~A}$ between neutral and recharged (during either a moderate La Niña or neutral state), two experiments similar to $\mathrm{MOD}_{R}$ (i.e., moderate La Niña and recharge), and one experiment similar to $\mathrm{MOD}_{D}$ (i.e., moderate discharge and El Niño).

Figures $9 b$ and $9 c$ respectively relate the increase in N3 SSTA spread between boreal spring and winter to the wind stress feedback and to the WEI spread across the ensemble. Figure $9 \mathrm{~b}$ first confirms that recharged experiments tend to be less predictable than discharged experiments (i.e., the red symbols tend to have higher IQR than the turquoise ones). The spread is low in all discharged experiments, but it covers a wider range of values in recharged experiments (e.g., extreme La Niña recharged $\mathrm{T} 300_{W} \mathrm{~A}$ states are almost as predictable as discharged states, evolving quite predictably into neutral event in our model; Figs. 4k,m). Across the experiments, there is a highly statistically significant link $(r \sim 0.9)$ between the spread increase during summer/autumn and both the wind stress feedback and WWE stochasticity. While this statistical link does not imply causality, it is consistent with the role of the multiplicative noise forcing and possible role of the wind stress feedback that we highlighted in the NEU, MOD, and EXT case studies.

\section{Summary}

The recharge oscillator theory (Jin 1997) indicates that a recharged equatorial western Pacific heat content (here defined by the depth averaged temperature in the upper $300 \mathrm{~m} ; \mathrm{T} 300_{W}$ ) promotes the occurrence of an El Niño a few seasons later, whereas a discharged heat content favors the occurrence of a $\mathrm{La}$ Niña. Recent studies (Planton et al. 2018; Larson and Kirtman 2019; Larson and Pegion 2020) debated whether the next ENSO phase is more predictable after a discharge than after a recharge, reaching no consensus. Further, these studies did not analyze the physical mechanisms that could lead to such a predictability asymmetry. The goal of the present study was to revisit this possible predictability asymmetry, and to propose an underlying mechanism. To do so, we designed a set of perfect model ensemble experiments with the CNRM-CM5 climate model, starting from either recharged or discharged western Pacific during boreal autumn and sampling the full range of corresponding ENSO phases. Our ensemble experiments demonstrate that, in the CNRM-CM5 model, discharged western Pacific initial conditions evolve more predictably into a neutral or La Niña state than recharged conditions into a neutral or El Niño state, regardless of the initial ENSO phase. This result is robust irrespective of whether we use a predictability metric that only accounts for the spread of the ensemble (PP) or also accounts for the SNR (although statistical significance is lower in that case). 

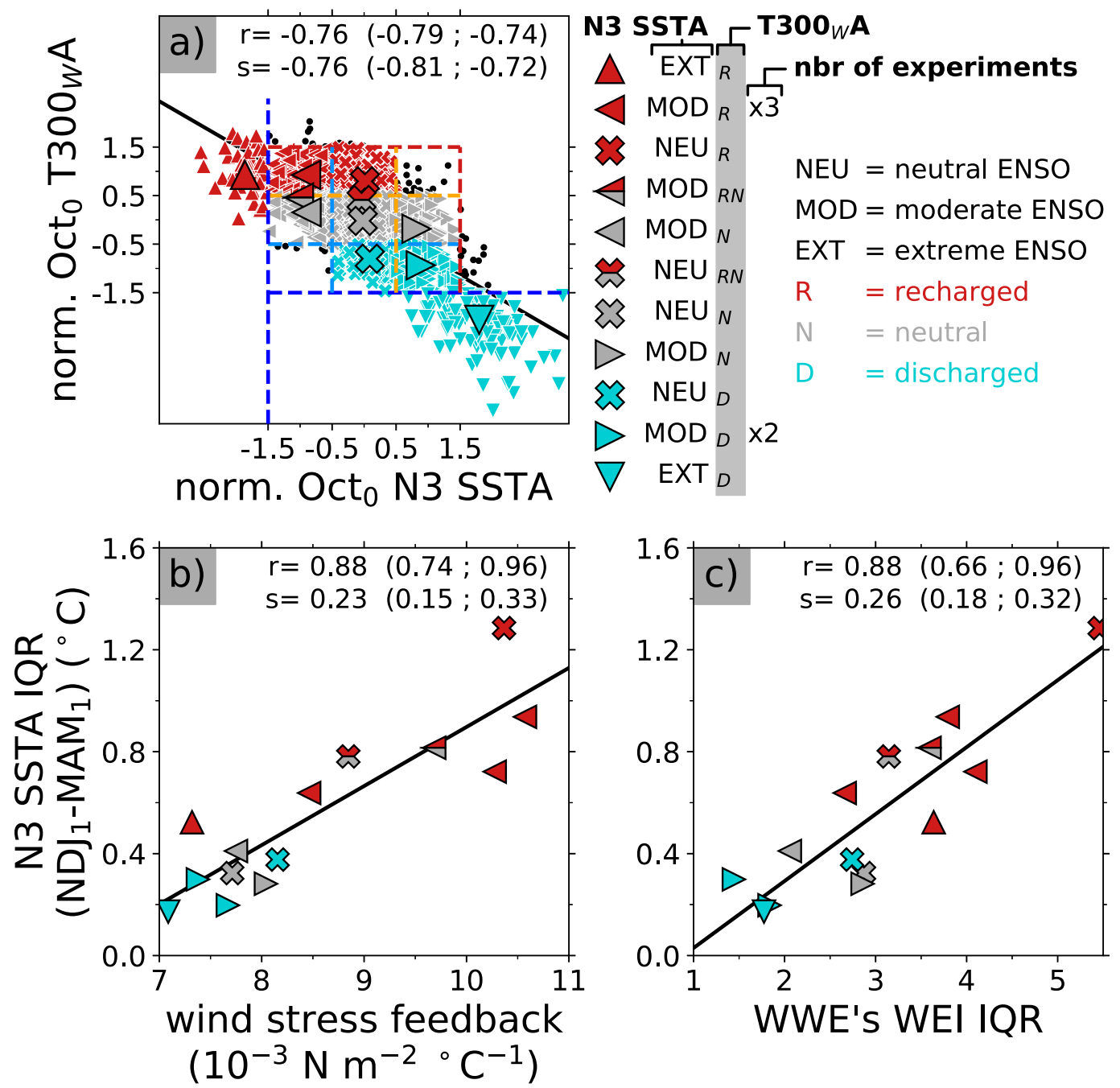

FIG. 9. (a) As in Fig. 3c but including the initial states of the additional ensemble experiments used in (b) and (c). Also shown are scatterplots between the ensemble spread evolution during boreal summer/autumn $\left(\mathrm{NDJ}_{1} \mathrm{~N}_{3}\right.$ SSTA IQR minus MAM $_{1}$ N3 SSTA IQR) and (b) April ${ }_{1}$-December ${ }_{1}$ wind stress feedback and (c) April ${ }_{1}-$ December ${ }_{1}$ integrated WEI index IQR. Black solid lines indicate the linear regression slopes. The corresponding $r$ and $s$ are indicated at the top of each panel, with the $95 \%$ confidence interval within parentheses.

The mechanisms that can explain the less predictable ENSO evolution in the recharged than in the discharged ensemble experiments can be summarized as follows (Fig. 10):

- Irrespective of the initial ENSO phase, the anomalously high western Pacific oceanic heat content in the recharged (discharged) experiments leads to warm (cold) central Pacific SSTA in boreal spring (preconditioning phase in Fig. 10), due to the thermocline and zonal advective feedbacks (Jin and An 1999; Jin et al. 2006). During this phase the ensemble spread of SSTA is similar in both types of experiments.

- During boreal spring, summer, and autumn (onset/growth phase in Fig. 10), the anomalously eastward WPEE in the recharged ensemble experiments leads to more active and more stochastic WWE (state-dependent forcing; e.g., Levine et al. 2016), promoting a larger growth of the ensemble spread (Fig. 4; see also Jin et al. 2007; Puy et al. 2019).
- During boreal autumn (growth phase in Fig. 10), the warmer surface temperature background also favors a stronger wind stress feedback in the recharged experiment during boreal autumn (e.g., Frauen and Dommenget 2010; Choi et al. 2013; Dommenget et al. 2013; Im et al. 2015; Takahashi and Dewitte 2016), but its effect is offset by a larger negative heat flux feedback (also related to the warmer background; e.g., Lloyd et al. 2012; Im et al. 2015) and weaker positive thermocline feedback (due to the deeper thermocline).

By the end of the year (peak in Fig. 10), this results in a larger spread and a less predictable ENSO state in the recharged than in the discharged ensemble experiments. In other words, a recharged state evolves less predictably toward a neutral or El Niño state than does a discharged state (toward a La Niña). 

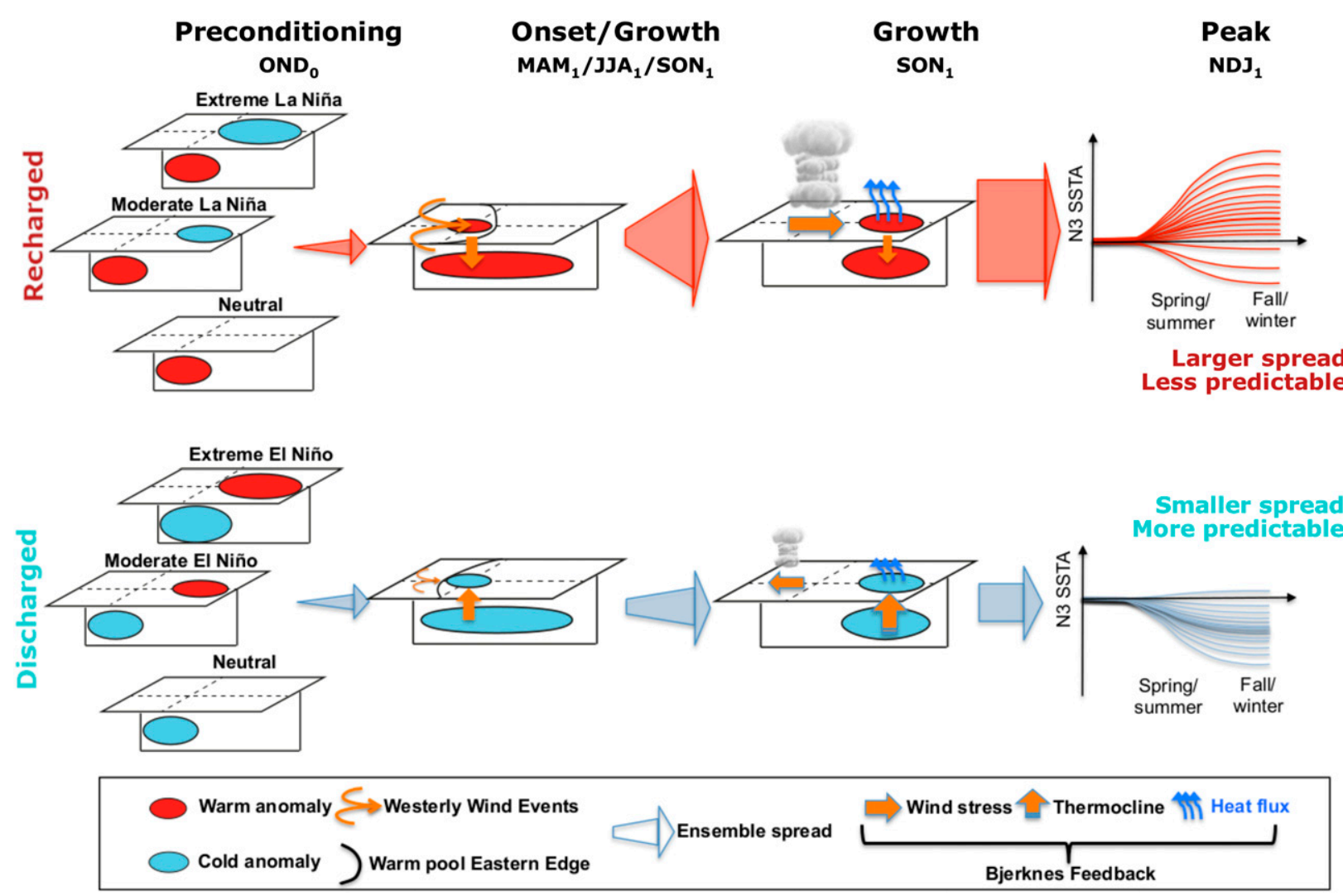

FIG. 10. Idealized schematic of the mechanisms influencing the predictability of ENSO depending on oceanic preconditioning. Preconditioning: recharged (at top)/discharged (at bottom) oceanic preconditioning associate with different ENSO states during boreal autumn. Onset/growth: influence of WWE on the development of SSTA spread during boreal spring, summer, and autumn. Growth: influence of the Bjerknes feedback on increasing SSTA spread during boreal autumn. Peak: ENSO plumes showing the larger spread and lower predictability of recharged states relative to discharged states.

\section{Discussion and perspectives}

The influence of oceanic preconditioning on asymmetries in long-term ENSO predictability has recently been debated, reaching no clear consensus. The potential asymmetry in ENSO predictability can be studied either based on predictability diagnostics in a perfect model setting (e.g., DiNezio et al. 2017a,b; Larson and Kirtman 2019; Yu and Fedorov 2020), like in the current study, or based on actual ENSO forecasts (e.g., Larson and Pegion 2020; Tippett et al. 2020). Let us discuss these approaches separately.

Our results with the CNRM-CM5 model confirm the statistical analyses of the CMIP database by Planton et al. (2018) and indicate a higher $\sim 1$-yr-lead predictability when starting from discharged rather than from recharged initial states. Jin et al. (2007) obtained similar results when they added a multiplicative noise forcing in the highly idealized recharge oscillator model. Yu and Fedorov (2020) found that the ENSO evolution in the CESM1.2 climate model was less predictable when starting from a recharged rather than from a neutral or discharged initial oceanic heat content. Our results also agree with those of DiNezio et al. (2017a,b), pointing to the high likelihood of a La Niña 1 year after an extreme discharge. Our ensemble experiment initialized from such conditions $\left(\mathrm{EXT}_{D}\right.$; Fig. $\left.4 \mathrm{~m}\right)$ indeed evolves into a moderate or extreme La Niña one year later in $97 \%$ of the cases. Lopez and Kirtman (2014) performed predictability experiments with the CCSM3 coupled models, in which a state-dependent WWE parameterization was added to compensate for the model's poor ability to reproduce observed WWE. When this parameterization is active, they find a more predictable cold phase, in agreement with our results, both in terms of the asymmetry predictability and of the role of WWE in this asymmetry. Larson and Kirtman (2019) also find a smaller spread in ensemble experiments with the CCSM4 model initialized from a discharge than in those initialized from a recharge (but defined using EP T300A). In contrast to our study, however, they find that the larger amplitude warm events result in a more favorable signal-to-noise ratio, and hence enhanced predictability when starting from a recharged state. The only study that partially differs with ours, by attributing a more predictable ENSO evolution after a recharged state, is thus that of Larson and Kirtman (2019). Their experimental setup is very similar to ours, so the difference must be attributable to model dependence of the results, arguing for more ENSO predictability studies using other models.

All of the studies above, however, focus on ENSO predictability, not actual predictions, and do not consider the effects of 
model errors, or those of initial oceanic condition uncertainties, which can also significantly contribute to ENSO forecast skill. Larson and Pegion (2020) used initialized predictions reproducing the setup of real-time seasonal ENSO forecasts. Using this more realistic setup, they pointed to equivalent ENSO predictability for recharged and discharged initial states. It is more difficult to know if this different result arises from the model they use or from the effect of oceanic initial condition uncertainties. Tippett et al. (2020) note that "false alarms" (when a forecast simulates a tendency that does not materialize) occur mostly in association with warming tendencies, which points toward a more predictable evolution toward negative SST anomalies, in agreement with our results.

Despite the relatively good performance of the CNRMCM5 model in comparison with other CMIP5 and CMIP6 models, it does underestimate several aspects of the observed ENSO asymmetry and the wind stress feedback. The strongly underestimated wind stress feedback in our model may for instance result in an underestimation of the role of the seasonal Bjerknes feedback relative to the ENSO state dependence of WWE in the mechanisms responsible for the asymmetry in predictability. Our model also overestimates the ENSO biennial tendency, largely due to too frequent La Niña to El Niño transitions ( $43 \%$ of the La Niña events in the model, $21 \%$ in the observations), while the El Niño to La Niña transitions are well represented (around $60 \%$ in the model and observations; Fig. 1). The too-frequent La Niña to El Niño transitions imply a more predictable evolution from initial western Pacific recharged states in CNRM-CM5 than in nature and thus do not challenge our result on the predictability asymmetry.

Our results highlight two processes able to enhance the spread of SSTA in recharged experiments: the seasonal wind stress feedback and the WWE. We emphasize more strongly the effect of WWE because 1) the differences in wind stress feedback between the recharged and discharged experiments tend to become significant after those in WEI and its spread and 2) the stronger (destabilizing) wind stress feedback occurs in conjunction with a stronger (stabilizing) heat flux feedback in all experiments, although we did not quantify the overall effect on predictability. In addition, WWE are associated with seasonal mean westerly winds, and hence contribute to the lowfrequency wind stress feedbacks during El Niño events. The wind stress feedback changes between discharged and recharged experiments become even less significant if we remove WWE before computing the wind stress feedback (not shown). While this strengthens our hypothesis about the dominant effect of the multiplicative noise, we admit there is some ambiguity and recognize that more research will be needed to further quantify the relative contributions of the seasonal Bjerknes feedback and the ENSO state dependence of WWE.

Our analysis indicates that asymmetrical WWE forcing, and possibly wind stress feedback, is likely to play a central role in the asymmetry of ENSO predictability. Such asymmetries arise from nonlinearities in ocean-atmosphere coupled dynamics. We did not, however, consider the full range of nonlinear coupled feedbacks that may contribute to asymmetries in ENSO predictability. The nonlinear dynamical heating (e.g., An and Jin 2004; Su et al. 2010) contribution to the advective feedback is indeed a warming process during both El Niño and La Niña; that is, it enhances the instability (and error growth) during warm events development and reduces it during cold events. It could thus also contribute to the less predictable recharged states evolution in the CNRM-CM5 model. Tropical instability waves (TIWs) also induce an asymmetrical heating in the cold tongue region between El Niño and La Niña (Wang and McPhaden 2000, 2001; Vialard et al. 2001). While TIWs provide a negative feedback to ENSO during both its warm and cold phases, this negative feedback is weaker during $\mathrm{El}$ Niño, favoring larger El Niño than La Niña events (e.g., An 2008). This enhanced warm event instability could therefore also contribute to the reduced predictability we see in the CNRM-CM5 model. But, on the other hand, the recent study by Holmes et al. (2019) also points out oceanic internal variability associated with TIWs in the eastern Pacific as a nonnegligible contributor to the ensemble spread in idealized experiments with a hybrid coupled model. This effect would work in the opposite direction, as TIWs are enhanced during La Niña. Clearly, more studies on the flow-dependent predictability of ENSO with various models and predictions systems are needed to fully understand the sign of the asymmetry in ENSO predictability and the underlying mechanisms.

Acknowledgments. We thank three anonymous reviewers of an earlier version of this paper for their insightful and constructive comments. We acknowledge the World Climate Research Programme's Working Group on Coupled Modelling, which is responsible for CMIP, and we thank the climate modeling groups (listed in Table 1) for producing and making available their model output. For CMIP the U.S. Department of Energy's Program for Climate Model Diagnosis and Intercomparison provides coordinating support and led development of software infrastructure in partnership with the Global Organization for Earth System Science Portals. The TropFlux data are produced under a collaboration between Laboratoire d'Océanographie: Expérimentation et Approches Numériques (LOCEAN) from Institut Pierre Simon Laplace (IPSL; Paris, France) and National Institute of Oceanography/ CSIR (NIO; Goa, India), and supported by Institut de Recherche pour le Développement (IRD; France). TropFlux relies on data provided by the ECMWF interim reanalysis (ERA-I) and ISCCP projects. GODAS data are provided by the NOAA/OAR/ESRL PSD. Author Planton holds a National Research Council Research Associateship Award at NOAA/ PMEL. We acknowledge the support from the Agence Nationale de la Recherche ARISE project, under Grant ANR-18-CE01-0012; the Belmont project GOTHAM, under Grant ANR-15-JCLI-0004-01; the "Make Our Planet Great Again" project ARCHANGE (Agence Nationale pour la Recherche project ANR-18-MPGA-0001); the Centre National de la Recherche Scientifique (CNRS); and the Institut de Recherche pour le Développement (IRD). The ESGF and IPSL/ESPRI-MOD data distribution systems are gratefully acknowledged. This is PMEL Contribution Number 5088.

Data availability statement. CMIP5 and CMIP6 data can be accessed at https://esgf-node.llnl.gov/projects/esgf-llnl/. TropFlux 
a) Observation

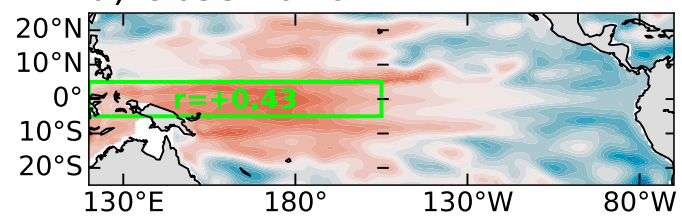

b) CNRM-CM5

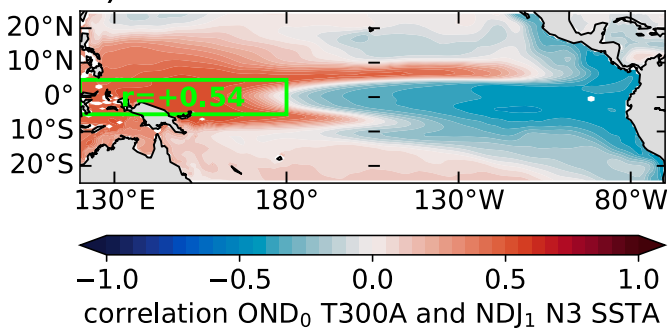

FIG. A1. Spatial structure of the correlation between $\mathrm{OND}_{0}$ T300A and $\mathrm{NDJ}_{1} \mathrm{~N} 3$ SSTA computed with (a) observations and (b) CNRM-CM5. Limits of the western equatorial Pacific region used for the observations and CNRM-CM5 are outlined in green. The correlation between $\mathrm{OND}_{0} \mathrm{~T}_{300} \mathrm{~A}$ and $\mathrm{NDJ}_{1} \mathrm{~N} 3 \mathrm{SSTA}$ is indicated in the box.

data can be downloaded from https:/incois.gov.in/tropflux/. GODAS data can be downloaded from https://www.esrl.noaa.gov/ psd/. Data from our simulations with the CNRM-CM5 global climate model, relevant to this paper, are published in Planton (2020), available at https://doi.org/10.17632/bsnd8md962.1.

\section{APPENDIX}

\section{Additional Details}

\section{a. CNRM-CM5 climate model}

The numerical simulations performed in this study use the CNRM-CM5 global climate model (Voldoire et al. 2013), one of the models that took part in the CMIP5 exercise (Taylor et al. 2012). Its oceanic component is the NEMO v3.2 ("Nucleus for European Modelling of the Ocean"; Madec et al. 2017) ocean general circulation model in its ORCA1 configuration (Hewitt et al. 2011). This configuration has a $1^{\circ}$ horizontal resolution, with a $1 / 3^{\circ}$ meridional refinement near the equator and 42 vertical levels, with a resolution ranging from $10 \mathrm{~m}$ near the surface to $300 \mathrm{~m}$ at $5000-\mathrm{m}$ depth. The vertical mixing parameterization uses a turbulent kinetic energy closure scheme (Blanke and Delecluse 1993). It is coupled to the atmospheric spectral general circulation model ARPEGEClimat v5.2 ("Action de Recherche Petite Echelle Grande Echelle"; Déqué et al. 1994) through the OASIS v3 coupler (Valcke 2013). The global spectral ARPEGE-Climat configuration has a $1.4^{\circ}$ horizontal resolution and 31 vertical levels, with resolution ranging from $10 \mathrm{~m}$ at the surface to $70 \mathrm{~km}$ at height. Deep atmospheric convection is parameterized following a mass convergence scheme (Bougeault 1985) with a humidity convergence closure. Large-scale precipitations are computed with a statistical precipitation scheme described by Smith (1990). A more detailed description of CNRM-CM5 can be found in Voldoire et al. (2013).

\section{b. Upper-ocean heat content}

The warm water volume of the entire equatorial Pacific region (WWV; volume of water warmer than $20^{\circ} \mathrm{C}$ within $120^{\circ} \mathrm{E}-80^{\circ} \mathrm{W}$, $5^{\circ} \mathrm{S}-5^{\circ} \mathrm{N}$ ) has been widely used as an index of the long-term recharge conceptualized in the recharge oscillator (Meinen and McPhaden 2000). Recent studies have, however, demonstrated that subsurface thermal anomalies in the western Pacific better encompass the lower-frequency ENSO dynamics (Ramesh and Murtugudde 2013; Lai et al. 2015; Ballester et al. 2016; Petrova et al. 2017; Planton et al. 2018; Izumo et al. 2019), as initially underlined by the seminal studies of Wyrtki (1985) and Jin (1997). Following these studies, the western equatorial Pacific index is used in this paper as a measure of the long-term oceanic preconditioning. We chose to measure subsurface thermal anomalies using the depth averaged temperature in the upper $300 \mathrm{~m}$ (T300) as it is easier to compute than WWV, and both quantities are highly correlated (above 0.9; e.g., Izumo et al. 2019; Larson and Pegion 2020; see also https://www.pmel.noaa.gov/elnino/upper-ocean-heat-content-andenso). Throughout this paper, "T300A" describes the spatiotemporal variability of T300 anomalies (used in Figs. 5a,b), "EP T300A" refers to the anomalies of T300 averaged over the entire equatorial Pacific region (index equivalent to WWV; used only in Fig. 3a or to compare our results with other studies), "T300 ${ }_{W} \mathrm{~A}$ " refers to the anomalies of T300 averaged over the western equatorial Pacific region (used to define the recharge/discharge level of the initial conditions of the ensemble experiments), and "N3 T300A" refers to the anomalies of T300 averaged over the Niño-3 region (used as a measure of thermocline depth anomalies to diagnose the thermocline feedback). Like many other models, CNRM-CM5 suffers from a "cold tongue bias" (e.g., Bellenger et al. 2014; Planton et al. 2020) that results in a westward shift of statistical link between T300A and ENSO 1 year later (Fig. A1). To account for this bias, the region over which $\mathrm{T} 300_{W} \mathrm{~A}$ is averaged was defined differently for CNRM-CM5 model $\left(120^{\circ} \mathrm{E}-180^{\circ}, 5^{\circ} \mathrm{S}-\right.$ $5^{\circ} \mathrm{N}$ ) and observations $\left[120^{\circ} \mathrm{E}-155^{\circ} \mathrm{W}, 5^{\circ} \mathrm{S}-5^{\circ} \mathrm{N}\right.$, as in Meinen and McPhaden (2000)].

\section{c. Metrics for ENSO predictability}

To estimate the predictability of ENSO events at the end of the ensemble experiments (predictability of NDJ N3 SSTA), we used two metrics:

- Potential predictability, defined as $\mathrm{PP}=1-\left(\mathrm{IQR}_{\text {expe }} /\right.$ $\left.I_{Q} R_{c t r l}\right)$, where $I Q R_{\text {expe }}$ and $I_{Q} R_{\text {ctrl }}$ are, respectively, the IQR of the given ensemble experiment (NDJ N3 SSTA at the end of the experiment) and that of the control simulation (every NDJ N3 SSTA of the control simulation). PP is thus similar to Kleeman (2002) but is based on IQR instead of 
variance. The idea is that when the ensemble has a spread $\left(\mathrm{IQR}_{\text {expe }}\right)$ as large as that of the control simulation $\left(\mathrm{IQR}_{\mathrm{ctrl}}\right)$, predictability is lost and $\mathrm{PP}=0$. The higher the $\mathrm{PP}$ value is, the more predictable is the experiment.

- Signal-to-noise ratio (SNR), defined as SNR $=\mid$ mean $_{\text {expe }} \mid$ $\mathrm{IQR}_{\text {expe }}$, where mean expe $_{\text {and }} \mathrm{IQR}_{\text {expe }}$ are, respectively, the ensemble mean value and the IQR of the given ensemble experiment and vertical bars indicate that the absolute value is taken. The idea is that if the ensemble mean is large, the ENSO signal is easily detectable even if the spread is large. The higher the SNR value is, the more predictable is the experiment.

Note that similar results are obtained if we use the standard deviation or the variance instead of the IQR to compute the predictability metrics, but we chose to show the computations with the IQR because several distributions are skewed.

\section{d. Statistical significance}

A nonparametric Monte Carlo method is used to estimate the statistical significance: 100000 random selections (with replacement) of any given sample are generated, providing the 2.5 th and 97.5 th percentiles of the distribution to obtain the 95\% confidence level. The same approach is used for estimating the statistical significance of the difference of the mean of the two distributions (e.g., the wind stress feedback in each experiment in Figs. 6, 7, and 8): the two samples are both randomly sampled 100000 times, the mean of their difference is computed, and the resulting distribution is used to compute the statistical significance.

\section{REFERENCES}

An, S.-I., 2008: Interannual variations of the tropical ocean instability wave and ENSO. J. Climate, 21, 3680-3686, https:// doi.org/10.1175/2008JCLI1701.1.

_ J. Climate, 17, 2399-2412, https://doi.org/10.1175/15200442(2004)017<2399:NAAOE > 2.0.CO;2.

— , E. Tziperman, Y. Okumura, and T. Li, 2020: ENSO irregularity and asymmetry. El Niño Southern Oscillation in a Changing Climate, Geophys. Monogr., Vol. 253, Amer. Geophys. Union, 153-172, https://doi.org/10.1002/9781119548164.ch7.

Ballester, J., D. Petrova, S. Bordoni, B. Cash, M. García-Díez, and X. Rodó, 2016: Sensitivity of El Niño intensity and timing to preceding subsurface heat magnitude. Sci. Rep., 6, 36344, https://doi.org/10.1038/srep36344.

Barnston, A. G., M. K. Tippett, M. Ranganathan, and M. L. L'Heureux, 2019: Deterministic skill of ENSO predictions from the North American multimodel ensemble. Climate Dyn., 53, 7215-7234, https://doi.org/10.1007/s00382-017-3603-3.

Bayr, T., C. Wengel, M. Latif, D. Dommenget, J. Lübbecke, and W. Park, 2019: Error compensation of ENSO atmospheric feedbacks in climate models and its influence on simulated ENSO dynamics. Climate Dyn., 53, 155-172, https://doi.org/ 10.1007/s00382-018-4575-7.

Bellenger, H., E. Guilyardi, J. Leloup, M. Lengaigne, and J. Vialard, 2014: ENSO representation in climate models: From CMIP3 to CMIP5. Climate Dyn., 42, 1999-2018, https://doi.org/10.1007/ s00382-013-1783-z.

Bertrand, A., M. Lengaigne, K. Takahashi, A. Avadí, F. Poulain, C. Harrod, 2020: El Niño Southern Oscillation (ENSO) effects on fisheries and aquaculture. FAO Fisheries and Aquaculture Tech. Paper 660, 264 pp., https://doi.org/10.4060/ca8348en.

Bjerknes, J., 1969: Atmospheric teleconnections from the equatorial Pacific. Mon. Wea. Rev., 97, 163-172, https://doi.org/ 10.1175/1520-0493(1969)097<0163:ATFTEP>2.3.CO;2.

Blanke, B., and P. Delecluse, 1993: Variability of the tropical Atlantic Ocean simulated by a general circulation model with two different mixed-layer physics. J. Phys. Oceanogr., 23, 1363-1388, https://doi.org/10.1175/1520-0485(1993)023<1363: VOTTAO $>2.0 . \mathrm{CO} ; 2$.

Bougeault, P., 1985: A simple parameterization of the largescale effects of cumulus convection. Mon. Wea. Rev., 113, 2108-2121, https://doi.org/10.1175/1520-0493(1985)113<2108: ASPOTL $>2.0 . \mathrm{CO} ; 2$.

Chiodi, A. M., and D. E. Harrison, 2015: Equatorial Pacific easterly wind surges and the onset of La Niña events. J. Climate, $\mathbf{2 8}$, 776-792, https://doi.org/10.1175/JCLI-D-14-00227.1.

- - - , and G. A. Vecchi, 2014: Subseasonal atmospheric variability and El Niño waveguide warming: Observed effects of the Madden-Julian oscillation and westerly wind events. J. Climate, 27, 3619-3642, https://doi.org/10.1175/JCLI-D-1300547.1.

Choi, K., G. A. Vecchi, and A. T. Wittenberg, 2013: ENSO transition, duration, and amplitude asymmetries: Role of the nonlinear wind stress coupling in a conceptual model. J. Climate, 26, 94629476, https://doi.org/10.1175/JCLI-D-13-00045.1.

Déqué, M., C. Dreveton, A. Braun, and D. Cariolle, 1994: The ARPEGE/IFS atmosphere model: A contribution to the French community climate modelling. Climate Dyn., 10, 249266, https://doi.org/10.1007/BF00208992.

DiNezio, P. N., and Coauthors, 2017a: A 2 year forecast for a 60$80 \%$ chance of La Niña in 2017-18. Geophys. Res. Lett., 44, 11 624-11 635, https://doi.org/10.1002/2017GL074904.

— C. C. Deser, Y. M. Okumura, and A. Karspeck, 2017b: Predictability of 2 year La Niña events in a coupled general circulation model. Climate Dyn., 49, 4237-4261, https://doi.org/ 10.1007/s00382-017-3575-3.

Dommenget, D., T. Bayr, and C. Frauen, 2013: Analysis of the nonlinearity in the pattern and time evolution of El Niño Southern Oscillation. Climate Dyn., 40, 2825-2847, https://doi.org/10.1007/ s00382-012-1475-0.

Eisenman, I., L. Yu, and E. Tziperman, 2005: Westerly wind bursts: ENSO's tail rather than the dog? J. Climate, 18, 5224-5238, https://doi.org/10.1175/JCLI3588.1.

Eyring, V., S. Bony, G. A. Meehl, C. A. Senior, B. Stevens, R. J. Stouffer, and K. E. Taylor, 2016: Overview of the Coupled Model Intercomparison Project phase 6 (CMIP6) experimental design and organization. Geosci. Model Dev., 9, 19371958, https://doi.org/10.5194/gmd-9-1937-2016.

Frauen, C., and D. Dommenget, 2010: El Niño and La Niña amplitude asymmetry caused by atmospheric feedbacks. Geophys. Res. Lett., 37, L18801, https://doi.org/10.1029/2010GL044444.

Gadgil, S., P. V. Joseph, and N. V. Joshi, 1984: Ocean-atmosphere coupling over monsoon regions. Nature, 312, 141-143, https:// doi.org/10.1038/312141a0.

Gebbie, G., I. Eisenman, A. T. Wittenberg, and E. Tziperman, 2007: Modulation of westerly wind bursts by sea surface temperature: A semistochastic feedback for ENSO. J. Atmos. Sci., 64, 3281-3295, https://doi.org/10.1175/JAS4029.1.

Goddard, L., and A. Gershunov, 2020: Impact of El Niño on weather and climate extremes. El Niño Southern Oscillation in a Changing Climate, Geophys. Monogr., Vol. 253, Amer. Geophys. Union, 361-375, https://doi.org/10.1002/9781119548164.ch16. 
Graham, N. E., and T. P. Barnett, 1987: Sea surface temperature, surface wind divergence, and convection over tropical oceans. Science, 238, 657-659, https://doi.org/10.1126/science.238.4827.657.

Guan, C., M. J. McPhaden, F. Wang, and S. Hu, 2019: Quantifying the role of oceanic feedbacks on ENSO asymmetry. Geophys. Res. Lett., 46, 2140-2148, https://doi.org/10.1029/2018GL081332.

Guilyardi, E., P. Braconnot, F.-F. Jin, S. T. Kim, M. Kolasinski, T. Li, and I. Musat, 2009: Atmosphere feedbacks during ENSO in a coupled GCM with a modified atmospheric convection scheme. J. Climate, 22, 5698-5718, https://doi.org/ 10.1175/2009JCLI2815.1.

Hewitt, H. T., D. Copsey, I. D. Culverwell, C. M. Harris, R. S. R. Hill, A. B. Keen, A. J. McLaren, and E. C. Hunke, 2011: Design and implementation of the infrastructure of HadGEM3: The nextgeneration Met Office climate modelling system. Geosci. Model Dev., 4, 223-253, https://doi.org/10.5194/gmd-4-223-2011.

Holbrook, N. J., and Coauthors, 2020: ENSO-driven ocean extremes and their ecosystem impacts. El Niño Southern Oscillation in a Changing Climate, Geophys. Monogr., Vol. 253, Amer. Geophys. Union, 409-428, https://doi.org/10.1002/ 9781119548164.ch18.

Holmes, R. M., S. McGregor, A. Santoso, and M. H. England, 2019: Contribution of tropical instability waves to ENSO irregularity. Climate Dyn., 52, 1837-1855, https://doi.org/10.1007/ s00382-018-4217-0.

Im, S.-H., S.-I. An, S. T. Kim, and F.-F. Jin, 2015: Feedback processes responsible for El Niño-La Niña amplitude asymmetry. Geophys. Res. Lett., 42, 5556-5563, https://doi.org/10.1002/ 2015 GL064853.

Izumo, T., M. Lengaigne, J. Vialard, I. Suresh, and Y. Planton, 2019: On the physical interpretation of the lead relation between warm water volume and the El Niño Southern Oscillation. Climate Dyn., 52, 2923-2942, https://doi.org/10.1007/s00382-018-4313-1.

Jin, F.-F., 1997: An equatorial ocean recharge paradigm for ENSO. Part I: Conceptual model. J. Atmos. Sci., 54, 811-829, https:// doi.org/10.1175/1520-0469(1997)054<0811:AEORPF>2.0.CO;2.

_ , and S.-I. An, 1999: Thermocline and zonal advective feedbacks within the equatorial ocean recharge oscillator model for ENSO. Geophys. Res. Lett., 26, 2989-2992, https://doi.org/ 10.1029/1999GL002297.

— , S. T. Kim, and L. Bejarano, 2006: A coupled-stability index for ENSO. Geophys. Res. Lett., 33, L23708, https://doi.org/ 10.1029/2006GL027221.

—, L. Lin, A. Timmermann, and J. Zhao, 2007: Ensemble-mean dynamics of the ENSO recharge oscillator under statedependent stochastic forcing. Geophys. Res. Lett., 34, L03807, https://doi.org/10.1029/2006GL027372.

Kleeman, R., 2002: Measuring dynamical prediction utility using relative entropy. J. Atmos. Sci., 59, 2057-2072, https://doi.org/ 10.1175/1520-0469(2002)059<2057:MDPUUR>2.0.CO;2.

Kokoska, S., and D. Zwillinger, 2000: CRC Standard Probability and Statistics Tables and Formulae: Student Edition. CRC Press, 200 pp., https://doi.org/10.1201/b16923.

Lai, A. W., M. Herzog, and H. Graf, 2015: Two key parameters for the El Niño continuum: Zonal wind anomalies and western Pacific subsurface potential temperature. Climate Dyn., 45, 3461-3480, https://doi.org/10.1007/s00382-015-2550-0.

Larson, S. M., and B. P. Kirtman, 2019: Linking preconditioning to extreme ENSO events and reduced ensemble spread. Climate Dyn., 52, 7417-7433, https://doi.org/10.1007/s00382-017-3791-x.

_ - and K. Pegion, 2020: Do asymmetries in ENSO predictability arise from different recharged states? Climate Dyn., 54, 15071522, https://doi.org/10.1007/s00382-019-05069-5.
Lengaigne, M., J.-P. Boulanger, C. Menkes, P. Delecluse, and J. Slingo, 2004: Westerly wind events in the tropical Pacific and their influence on the coupled ocean-atmosphere system: A review. Earth's Climate: The Ocean-Atmosphere Interaction, Geophys. Monogr., Vol. 147, Amer. Geophys. Union, 49-69, https://doi.org/10.1029/147GM03.

Levine, A. F. Z., F.-F. Jin, and M. J. McPhaden, 2016: Extreme noise-extreme El Niño: How state-dependent noise forcing creates El Niño-La Niña asymmetry. J. Climate, 29, 54835499, https://doi.org/10.1175/JCLI-D-16-0091.1.

L'Heureux, M. L., A. F. Z. Levine, M. Newman, C. Ganter, J.-J. Luo, M. K. Tippett, and T. N. Stockdale, 2020: ENSO prediction. El Niño Southern Oscillation in a Changing Climate, Geophys. Monogr., Vol. 253, Amer. Geophys. Union, 227246, https://doi.org/10.1002/9781119548164.ch10.

Lin, I.-I., and Coauthors, 2020: ENSO and tropical cyclones. El Niño Southern Oscillation in a Changing Climate, Geophys. Monogr., Vol. 253, Amer. Geophys. Union, 377-408, https:// doi.org/10.1002/9781119548164.ch17.

Lloyd, J., E. Guilyardi, H. Weller, and J. Slingo, 2009: The role of atmosphere feedbacks during ENSO in the CMIP3 models. Atmos. Sci. Lett., 10, 170-176, https://doi.org/10.1002/asl.227.

- ——, and — , 2012: The role of atmosphere feedbacks during ENSO in the CMIP3 models. Part III: The shortwave flux feedback. J. Climate, 25, 4275-4293, https://doi.org/10.1175/ JCLI-D-11-00178.1.

Lopez, H., and B. P. Kirtman, 2014: WWBs, ENSO predictability, the spring barrier and extreme events. J. Geophys. Res. Atmos., 119, 10114-10, https://doi.org/10.1002/2014JD021908.

Madec, G., and Coauthors, 2017: NEMO ocean engine (version v3.6-patch). Note du pôle de modélisation de L'Institut PierreSimon Laplace (IPSL) No. 27, 402 pp., https://doi.org/10.5281/ zenodo.3248739.

Martinez-Villalobos, C., M. Newman, D. J. Vimont, C. Penland, and J. D. Neelin, 2019: Observed El Niño-La Niña asymmetry in a linear model. Geophys. Res. Lett., 46, 9909-9919, https:// doi.org/10.1029/2019GL082922.

McGregor, S., A. Timmermann, F.-F. Jin, and W. S. Kessler, 2016: Charging El Niño with off-equatorial westerly wind events. Climate Dyn., 47, 1111-1125, https://doi.org/10.1007/s00382015-2891-8.

McPhaden, M. J., 2015: Playing hide and seek with El Niño. Nat. Climate Change, 5, 791-795, https://doi.org/10.1038/nclimate2775.

_- A. Santoso, and W. Cai, 2020: El Niño Southern Oscillation in a Changing Climate. Geophys. Monogr., Vol. 253, Amer. Geophys. Union, 528 pp., https://doi.org/10.1002/9781119548164.

Meinen, C. S., and M. J. McPhaden, 2000: Observations of warm water volume changes in the equatorial Pacific and their relationship to El Niño and La Nina. J. Climate, 13, 3551-3559, https://doi.org/10.1175/1520-0442(2000)013<3551: OOWWVC $>2.0 . \mathrm{CO} ; 2$.

Neske, S., and S. McGregor, 2018: Understanding the warm water volume precursor of ENSO events and its interdecadal variation. Geophys. Res. Lett., 45, 1577-1585, https://doi.org/ 10.1002/2017GL076439.

Petrova, D., S. Koopman, J. Ballester, and X. Rodó, 2017: Improving the long-lead predictability of El Niño using a novel forecasting scheme based on a dynamic components model. Climate Dyn., 48, 1249-1276, https://doi.org/10.1007/ s00382-016-3139-y.

Planton, Y. Y., 2020: CNRM-CM5_for_ENSO_predictability. Mendeley Data, V1, accessed 2020, https://doi.org/10.17632/ bsnd8md962.1. 
J. Vialard, E. Guilyardi, M. Lengaigne, and T. Izumo, 2018: Western Pacific oceanic heat content: A better predictor of $\mathrm{La}$ Niña than of El Niño. Geophys. Res. Lett., 45, 9824-9833, https://doi.org/10.1029/2018GL079341.

— CLIVAR 2020 ENSO metrics package. Bull. Amer. Meteor. Soc, 102, E193-E217, https://doi.org/10.1175/BAMS-D-19-0337.1.

Praveen Kumar, B., J. Vialard, M. Lengaigne, V. S. N. Murty, and M. J. McPhaden, 2012: TropFlux: Air-sea fluxes for the global tropical oceans-Description and evaluation. Climate Dyn., 38, 1521-1543, https://doi.org/10.1007/s00382-011-1115-0.

,,,,---- M. F. Cronin, F. Pinsard, and K. Gopala Reddy, 2013: TropFlux wind stresses over the tropical oceans: Evaluation and comparison with other products. Climate Dyn., 40, 2049-2071, https://doi.org/10.1007/ s00382-012-1455-4.

Puy, M., 2016: L'influence des coups de vent d'ouest dans le Pacifique équatorial sur El Niño: Origines atmosphériques et impacts océaniques. Doctoral dissertation, Université Pierre et Marie Curie-Paris VI, 224 pp., https://tel.archivesouvertes.fr/tel-01360580/document.

__, J. Vialard, M. Lengaigne, and E. Guilyardi, 2016: Modulation of equatorial Pacific westerly/easterly wind events by the Madden-Julian oscillation and convectively-coupled Rossby waves. Climate Dyn., 46, 2155-2178, https://doi.org/10.1007/ s00382-015-2695-x.

- and Coauthors, 2019: Influence of westerly wind events stochasticity on El Niño amplitude: The case of 2014 vs. 2015. Climate Dyn., 52, 7435-7454, https://doi.org/10.1007/s00382017-3938-9.

Ramesh, N., and R. Murtugudde, 2013: All flavours of El Niño have similar early subsurface origins. Nat. Climate Change, 3, 42-46, https://doi.org/10.1038/nclimate1600.

Saha, S., and Coauthors, 2006: The NCEP Climate Forecast System. J. Climate, 19, 3483-3517, https://doi.org/10.1175/JCLI3812.1.

Smith, R. N. B., 1990: A scheme for predicting layer clouds and their water content in a general circulation model. Quart. J. Roy. Meteor. Soc., 116, 435-460, https://doi.org/10.1002/qj.49711649210.

Su, J., R. Zhang, T. Li, X. Rong, J.-S. Kug, and C.-C. Hong, 2010: Causes of the El Niño and La Niña amplitude asymmetry in the equatorial eastern Pacific. J. Climate, 23, 605-617, https:// doi.org/10.1175/2009JCLI2894.1.

Takahashi, K., and B. Dewitte, 2016: Strong and moderate nonlinear El Niño regimes. Climate Dyn., 46, 1627-1645, https:// doi.org/10.1007/s00382-015-2665-3.
Taschetto, A. S., C. C. Ummenhofer, M. F. Stuecker, D. Dommenget, K. Ashok, R. R. Rodrigues, and S. W. Yeh, 2020: ENSO atmospheric teleconnections. El Niño Southern Oscillation in a Changing Climate, Geophys. Monogr., Vol. 253, Amer. Geophys. Union, 309-335, https://doi.org/10.1002/9781119548164.ch14.

Taylor, K. E., R. J. Stouffer, and G. A. Meehl, 2012: An overview of CMIP5 and the experiment design. Bull. Amer. Meteor. Soc., 93, 485-498, https://doi.org/10.1175/BAMS-D-11-00094.1.

Timmermann, A., and Coauthors, 2018: El Niño-Southern Oscillation complexity. Nature, 559, 535-545, https://doi.org/10.1038/s41586018-0252-6.

Tippett, M. K., M. L. L'Heureux, E. J. Becker, A. Kumar, 2020: Excessive momentum and false alarms in late-spring ENSO forecasts. Geophys. Res. Lett., 47, e2020GL087008, https:// doi.org/10.1029/2020GL087008.

Valcke, S., 2013: The OASIS3 coupler: A European climate modelling community software. Geosci. Model Dev., 6, 373388, https://doi.org/10.5194/gmd-6-373-2013.

Vialard, J., C. Menkes, J.-P. Boulanger, P. Delecluse, E. Guilyardi, M. J. McPhaden, and G. Madec, 2001: A model study of oceanic mechanisms affecting equatorial Pacific sea surface temperature during the 1997-98 El Niño. J. Phys. Oceanogr., 31, 1649-1675, https://doi.org/10.1175/1520-0485(2001)031<1649: AMSOOM $>2.0 . \mathrm{CO} ; 2$.

Voldoire, A., and Coauthors, 2013: The CNRM-CM5.1 global climate model: Description and basic evaluation. Climate Dyn., 40, 2091-2121, https://doi.org/10.1007/s00382-011-1259-y.

Wang, W., and M. J. McPhaden, 2000: The surface layer heat balance in the equatorial Pacific Ocean, Part II: Interannual variability. J. Phys. Oceanogr., 30, 2989-3008, https://doi.org/ 10.1175/1520-0485(2001)031<2989:TSLHBI > 2.0.CO;2.

— , and _ 2001: Surface layer heat balance in the equatorial Pacific Ocean during the 1997-98 El Niño and the 1998-99 La Niña. J. Climate, 14, 3393-3407, https://doi.org/10.1175/15200442(2001)014<3393:SLTBIT>2.0.CO;2.

Webster, P. J., and S. Yang, 1992: Monsoon and ENSO: Selectively interactive systems. Quart. J. Roy. Meteor. Soc., 118, 877-926, https://doi.org/10.1002/qj.49711850705.

Wyrtki, K., 1985: Water displacements in the Pacific and the genesis of El Nino cycles. J. Geophys. Res., 90, 7129-7132, https:// doi.org/10.1029/JC090iC04p07129.

Yu, S., and A. V. Fedorov, 2020: The role of westerly wind bursts during different seasons versus ocean heat recharge in the development of extreme El Niño in climate models. Geophys. Res. Lett., 47, e2020GL088381, https://doi.org/10.1029/2020GL088381. 